\title{
Vapor Pressure Formulation for Ice
}

\author{
Arnold Wexler \\ Institute for Basic Standards, National Bureau of Standards, Washignton, D.C. 20234
}

(September 23, 1976)

\begin{abstract}
A new formulation is presented for the vapor pressure of ice from the triple point to $-100{ }^{\circ} \mathrm{C}$ based on thermodynamic calculations. Use is made of the definitive experimental value of the vapor pressure of water at its triple point recently obtained by Guildner, Johnson, and Jones. A table is given of the vapor pressure as a function of temperature at 0.1 -degree intervals over the range 0 to $-100{ }^{\circ} \mathrm{C}$, together with the values of the temperature derivative at l-degree intervals. The formulation is compared with published experimental measurements and vapor pressure equations. It is estimated that this formulation predicts the vapor pressure of ice with an overall uncertainty that varies from 0.016 percent at the triple point to 0.50 percent at $-100{ }^{\circ} \mathrm{C}$.
\end{abstract}

Key words: Clausius-Clapeyron equation; saturation vapor pressure over ice; thermal properties of ice; vapor pressure; vapor pressure at the triple point; vapor pressure of ice; water vapor.

\section{Introduction}

In meteorology, air conditioning, and hygrometry, particularly in the maintenance and use of standards and generators in calibrations and in precision measurements, accurate values of the vapor pressure of the pure water-substance are essential. Because of this Wexler and Greenspan $[1]^{1}$ recently published a new vapor pressure formulation for the pure liquid phase, based on thermodynamic calculations, which is in excellent agreement from 25 to $100{ }^{\circ} \mathrm{C}$ with the precise measurements of Stimson [2]. Wexler [3] subsequently revised this formulation to make it consistent with the definitive experimental value of the vapor pressure of water at its triple point obtained by Guildner, Johnson, and Jones. The purpose of this present paper is to apply a similar method of calculation to the pure ice phase and derive a new formulation for temperatures down to $-100{ }^{\circ} \mathrm{C}$. This new formulation for ice is constrained to yield the identical value of vapor pressure at the triple point as that given by the revised formulation for the liquid phase.

A critical examination of the experimental vapor-pressure data of ice discloses the disconcerting fact that the dispersion among those values far exceeds modern accuracy requirements. This dispersion arises, in part, from the inherent difficulties experienced by investigators in making precision measurements of these low pressures and from the ambiguities in the temperature scale used in the early 1900's when several major series of determinations were made. Thermodynamic calculations, based on accurate thermal data, provide an alternate route to the determination of vapor pressure. It is therefore not surprising that such calculations have been made repeatedly for ice with varying degrees of success. It is interesting to note that these calculations have been preferred over the existent experimental vapor pressures, primarily because the calculations appear to yield less uncertainty than the measurements.

${ }^{1}$ Figures in brackets indicate the literature references at the end of this paper.

\section{Derivation}

The Clausius-Clapeyron equation, when applied to the solid-vapor phase transition for the pure water-substance, may be written

$$
\frac{d p}{d T}=\frac{l}{T\left(v-v^{\prime \prime}\right)}
$$

where $p$ is the pressure of the saturated vapor, $v$ is the specific volume of the saturated vapor, $v^{\prime \prime}$ is the specific volume of the saturated ice, $T$ is the absolute thermodynamic temperature, $l$ is the latent heat of sublimation, and $d p / d T$ is the derivative of the vapor pressure with respect to temperature. The latent heat of sublimation is given by

$$
l=h-h^{\prime \prime}
$$

where $h$ is the specific enthalpy of saturated water vapor at temperature $T$ and $h^{\prime \prime}$ is the specific enthalpy of saturated ice at the same temperature $T$.

The equation of state for saturated water vapor may be expressed by

$$
p v=Z R T
$$

where $Z$ is the compressibility factor and $R$ is the specific gas constant. When eq (3) is substituted into eq (1) the result is

$$
\frac{d p}{p}=\frac{l}{Z R T^{2}}\left(1+\frac{v^{\prime \prime}}{v}\right) d T
$$

where higher order terms of $v^{\prime \prime} / v$ are neglected because $v^{\prime \prime} / v$ $<1$. On integrating, eq (4) becomes

$$
\int_{\boldsymbol{p}_{1}}^{\boldsymbol{p}_{2}} d(\ln p)=\int_{T_{1}}^{T_{2}} \frac{l}{Z R T^{2}}\left(1+\frac{v^{\prime \prime}}{v}\right) d T
$$


where $p_{1}$ and $p_{2}$ are the saturation vapor pressures at temperatures $T_{1}$ and $T_{2}$, respectively. Suitable functions will be sought for $Z, v, v^{\prime \prime}$ and $l$ in order to complete the integration of eq (5).

Functions for the compressibility factor $Z$ and the specific volume of saturated water vapor $v$ will be based on a virial equation of state expressed as a power series in $p$. A function for the specific volume of saturated ice $v^{\prime \prime}$ will be developed from experimental data for the coefficient of linear expansion and the density at $0{ }^{\circ} \mathrm{C}$. A function for the latent heat of sublimation $l$ will be derived from the specific enthalpies $h^{\prime \prime}$ and $h$ of saturated ice and saturated water vapor, respectively. Use will be made of measurements of the specific heat of ice to obtain $h^{\prime \prime}$ whereas statistical mechanical calculations of the ideal-gas (zero-pressure) specific heat of water will serve as input data for establishing an expression for $h$.

\subsection{Temperature}

Guildner and Edsinger [5] have recently made measurements on the realization of the thermodynamic temperature scale from 273.16 to $730 \mathrm{~K}$ by means of gas thermometry. Unfortunately there are no similar high precision measurements below $273.16 \mathrm{~K}$. Therefore, it will be assumed that the International Practical Temperature Scale of 1968 (IPTS-68) [6] is a sufficiently close approximation to the absolute thermodynamic temperature so that the thermal quantities given in terms of IPTS-68 can be used in eq (5). From the triple point to $-100{ }^{\circ} \mathrm{C}$ the temperature $t$ in degrees Celsius has the same numerical values on the International Temperature Scale of 1927 (ITS-27) [7], the International Temperature Scale of 1948 (ITS-48) [8] and the International Practical Temperature Scale of 1948 (IPTS-48) [9]. However, the ice point on IPTS-48 is defined as equal to 273.15 kelvins whereas on ITS-27 and ITS-48 it is defined as equal to 273.16 kelvins. The difference $T_{68}-T_{48}$, where $T_{68}$ and $T_{48}$ are the kelvin temperatures on IPTS-68 and IPTS-48, respectively, in the range of interest reaches a maximum of 0.0336 kelvin at $200 \mathrm{~K}[10,11]$. Using the corrections given by Riddle, Furukawa, and Plumb [11], temperatures on ITS-27, ITS-48 and IPTS-48 have been converted to IPTS-68 where needed in the calculations.

\subsection{Specific Volume of Saturated Vapor}

Equation (3) is used to calculate the specific volume of saturated water vapor $v$. The compressibility factor $Z$ is expressed as a power series in $p$

$$
Z=1+B^{\prime} p+C^{\prime} p^{2}+\cdots
$$

where $B^{\prime}$ is the second pressure-series virial coefficient and $C^{\prime}$ is the third pressure-series virial coefficient. The contribution of $C^{\prime} p^{2}$ to $Z$ is only a few parts per million at the triple point and less at lower temperatures and so has negligible effect. The empirical relationship for the second virial coefficient is based on experimental data obtained at elevated temperatures. This equation will be extrapolated below $0{ }^{\circ} \mathrm{C}$ with the full recognition that this may lead to large uncertainties in the virial coefficients. Although $B^{\prime}$ rapidly increases in magnitude with decreasing temperature, the saturation vapor pressure decreases even more rapidly so that $Z$ rapidly approaches its limiting value of unity as the temperature drops. Saturated water vapor, therefore, tends to behave more and more like an ideal gas as the temperature decreases, thereby reducing the effect of errors in $B^{\prime}$.

Table 1 shows a comparison of $Z$ from the triple point to $-100{ }^{\circ} \mathrm{C}$, for water vapor saturated with respect to ice, calculated using the empirical second virial coefficient equations of Goff and Gratch [12, 13, 14], Keyes [15, 16], and Juza as given by Bain [17]. The maximum difference in $Z$, as well as $v$, is $118 \mathrm{ppm}$ and occurs at $0.01{ }^{\circ} \mathrm{C}$. This can be used as an indication of uncertainty although the actual error is indeterminate. The differences decrease as the temperature decreases. At $-70{ }^{\circ} \mathrm{C}$ and below, the differences are equal to, or less than, one ppm since, at such temperatures, the second virial coefficient makes a negligible contribution to $Z$.

TABLE 1. Compressibility factor for saturated water vapor over ice

\begin{tabular}{|c|c|c|c|c|}
\hline Temperature & & Compressi & ty Factor ${ }^{a}$ & \\
\hline${ }^{\circ} \mathrm{C}$ & $\begin{array}{c}\text { Keyes } \\
1969^{b} \\
Z\end{array}$ & $\begin{array}{c}\text { Keyes } \\
1947^{\circ} \\
Z\end{array}$ & Bain $^{d}$ & $\begin{array}{c}\text { Goff } \\
\text { and } \\
\text { Gratch }^{e} \\
\text { Z }\end{array}$ \\
\hline 0.01 & 0.999624 & 0.999501 & 0.999529 & 0.999506 \\
\hline 0 & .999624 & .999501 & .999529 & .999506 \\
\hline-10 & .999907 & .999726 & .999747 & .999730 \\
\hline-20 & 999958 & .999856 & .999871 & .999859 \\
\hline-30 & 999982 & .999928 & .999938 & .999930 \\
\hline-40 & 999993 & .999966 & .999972 & .999967 \\
\hline-50 & 999998 & .999984 & .999986 & .999985 \\
\hline-60 & .999999 & .999994 & .999996 & .999994 \\
\hline-70 & 1.000000 & .999997 & 999999 & .999998 \\
\hline-80 & 1.000000 & .999999 & 1.000000 & .999999 \\
\hline-90 & 1.000000 & 1.000000 & 1.000000 & 1.000000 \\
\hline-100 & 1.000000 & 1.000000 & 1.000000 & 1.000000 \\
\hline
\end{tabular}

a Calculated by eq (6) using $B^{\prime}$ given by the indicated investigator.

$b$ Ref [16].

c Ref [15].

d Ref [17].

e Ref [12-14].

The 1969 second virial coefficient of Keyes [16] will be used in order to be consistent with the earlier use of this same coefficient [3]. His virial coefficient equation, converted to SI units compatible with eq (6), is

$$
\begin{aligned}
B^{\prime}=\left[\frac{0.44687}{T}-\left(\frac{565.965}{T^{2}}\right)\right. & \\
& \left.\times 10 \frac{100800}{34900+T^{2}}\right] \times 10^{-5} .
\end{aligned}
$$

where $B^{\prime}$ is in units of reciprocal pressure $(\mathrm{Pa})^{-1} \cdot{ }^{2}$

\subsection{Specific Volume of Saturated Ice}

Only hexagonal Ice-I will be of concern. It will be assumed that the crystals are randomly aligned with respect to the optic axis. All known measurements of the density of ice have been made in the presence of an inert gas, usually at a pressure of one atmosphere and at a temperature of $0{ }^{\circ} \mathrm{C}$.

\footnotetext{
${ }^{2} 1 \mathrm{~Pa}=1 \mathrm{~V} / \mathrm{m}^{2}=10^{-5} \mathrm{bar}=10^{-2} \mathrm{mb}=7.50062 \times 10^{-3} \mathrm{~mm} \mathrm{Hg}$.
} 
Dorsey [18] has compiled an extensive list of such determinations. Ginnings and Corruccini [19] using a Bunsen ice calorimeter, obtained a value at $0{ }^{\circ} \mathrm{C}$ and one atmosphere ${ }^{3}$ of $0.91671 \mathrm{~g} / \mathrm{ml}$. This value is definitive and supersedes all earlier measurements. Using this value and the coefficient of linear expansion of ice, the specific volume was calculated at temperatures below $0{ }^{\circ} \mathrm{C}$ as follows.

The isopiestic coefficient of linear expansion of ice $\alpha_{P}$ is defined by the equation

$$
\alpha_{P}=\left(\frac{1}{\lambda_{i}} \frac{d \lambda}{d T}\right)_{P}
$$

where $\lambda_{i}$ is the initial length of a specimen at the ice point temperature, $\lambda$ is the length of the same specimen at temperature $T$ and $d \lambda / d T$ is the rate of thermal expansion. By integrating eq (8), cubing the resultant equation, neglecting higher order terms in $\int_{T_{i}} \alpha_{P} d T$, it follows that

$$
v_{P, T}^{\prime \prime}=v_{P, T_{i}}^{\prime \prime}\left[1+3 \int_{T_{i}}^{T} \alpha_{P} d T\right]
$$

where $v^{\prime \prime}{ }_{P, T}$ is the specific volume of ice at pressure $P$ and temperature $T, v_{P, T_{i}}^{\prime \prime}$ is the specific volume of ice at pressure $P$ and at the ice point temperature $T_{i}$.

There are several series of measurements of the coefficient of linear expansion of hexagonal Ice-I at atmospheric pressure. The data of Jakob and Erk [20], Powell [21], Butkovich [22], Dantl [23], and LaPlaca and Post [24] were fitted to a linear equation by the method of least squares. The result is

$$
\alpha_{P_{a}} \times 10^{6}=-7.6370+0.227097 T
$$

which, when substituted into eq (9) together with the Ginnings and Corruccini value ${ }^{4}$ for the density of ice at $0^{\circ} \mathrm{C}$ and one atmosphere becomes

$$
\begin{aligned}
v_{P_{a}, T}^{\prime \prime}=1.069989-0.249933 & \times 10^{-4} T \\
& +0.371606 \times 10^{-6} T^{2}
\end{aligned}
$$

where $v^{\prime \prime} P_{a}, T$, expressed in $\mathrm{cm}^{3} / \mathrm{g}$, is the specific volume at atmospheric pressure, i.e., $101325 \mathrm{~Pa}$, and temperature $T$. It is the specific volume at saturation rather than at atmospheric pressure that is needed. The specific volume at a given pressure can be corrected to that at another pressure from a knowledge of the isothermal compressibility $k$, which is given by the equation

$$
k=k_{s}+\frac{T v^{\prime \prime} \beta^{2}}{c_{P}^{\prime \prime}}
$$

where $k_{s}$ is the adiabatic compressibility, $T$ is the absolute

\footnotetext{
${ }^{3} 1$ atmosphere $=101325$ pascals

${ }^{4}$ The density was converted from $\mathrm{g} / \mathrm{ml}$ to $\mathrm{g} / \mathrm{cm}^{3}$ by using the factor $1 \mathrm{ml}=1.000028 \mathrm{~cm}^{3}[25]$.
}

temperature, $v^{\prime \prime}$ is the specific volume, $\beta$ is the volume expansivity, and $c^{\prime \prime}{ }_{P}$ is the specific heat at constant pressure. Values of the isothermal compressibility of ice were calculated by using Leadbetter's values [27] for the adiabatic compressibility of Ice-I, eq (11) to obtain the specific volume at pressure $P_{a}$ and temperature $T$, eq (10) to obtain $\beta(=$ $3 \alpha_{P_{a}}$ ), and eq (19) (which is derived later) to obtain the specific heat at constant pressure $P_{a}$. The results for the temperature range of interest are given by the linear equation

$$
k=(8.875+0.0165 T) \times 10^{-11}
$$

where $k$ is expressed in units of $(\mathrm{Pa})^{-1}$. The specific volume of ice at pressure $P$ and temperature $T$ is therefore $v_{P, T}^{\prime \prime}=$ $v^{\prime \prime} P_{a}, T\left[1-k\left(P-P_{a}\right)\right]$ so that

$$
\begin{aligned}
v_{P, T}^{\prime \prime}=v_{P_{a}, T}^{\prime \prime}[1-(8.875+0.0165 T)(P- & 101325) \\
& \left.\times 10^{-11}\right]
\end{aligned}
$$

where $P$ is expressed in $\mathrm{Pa}$. If the saturated vapor pressure $p$ is inserted for $P$, then eq (14) yields the pure phase specific volume $v^{\prime \prime}$ at saturation. Over the temperature range 173.15 to $273.16 \mathrm{~K}$ the numerical value of the bracket is equal to 1.000013 with a maximum variability of one ppm. Using this value yields

$$
\begin{aligned}
v_{P, T}^{\prime \prime}=v^{\prime \prime}=1.070003-0.249936 \times 10^{-4} T \\
+0.371611 \times 10^{-6} T^{2} .
\end{aligned}
$$

\subsection{Enthalpy of Ice}

It can be shown [26] that the specific enthalpy $h^{\prime \prime}$ of the solid phase of a pure substance, say ice, is given by the relationship

$$
d h^{\prime \prime}=c_{P}^{\prime \prime} d T+v_{T}^{\prime \prime} d P-T\left(\frac{\partial v_{T}^{\prime \prime}}{\partial T}\right)_{P} d P
$$

where $c^{\prime \prime}{ }_{P}$ is the specific heat of ice at constant pressure $P$. When integrated this equation becomes

$$
\int_{h^{\prime \prime}}^{h_{1}{ }_{2}} d h^{\prime \prime}=\int_{T_{1}}^{T_{2}} c_{P}^{\prime \prime} d T+\int_{P_{1}}^{P_{2}}\left[v^{\prime \prime}-T\left(\frac{\partial v^{\prime \prime}}{\partial T}\right)_{P}\right]_{T} d P
$$

Because eq (17) represents a system undergoing a reversible process between two equilibrium states, the initial and final enthalpies are independent of the path. Therefore, a path is chosen which starts on the saturation curve at $\left(T_{i}, p_{i}\right)$, moves isothermally to $\left(T_{i}, P_{a}\right)$, then proceeds isobarically to $\left(T, P_{a}\right)$, and finally goes isothermally to $(T, p)$. The integration along this path is given by 


$$
\begin{aligned}
h^{\prime \prime}-h^{\prime \prime}{ }_{i} & =\int_{\boldsymbol{p}_{i}}^{P_{a}}\left[v^{\prime \prime}-T\left(\frac{\partial v^{\prime \prime}}{\partial T}\right)_{p_{i}}\right]_{T_{i}} d P \\
& +\int_{p_{i}}^{T} c^{\prime \prime} P_{a} d T+\int_{P_{a}}^{p}\left[v^{\prime \prime}-T\left(\frac{\partial v^{\prime \prime}}{\partial T}\right)_{P_{a}}\right]_{T} d P .
\end{aligned}
$$

If $p_{i}$ is the saturation vapor pressure at the ice-point temperature $T_{i}, p$ is the saturation vapor pressure at temperature $T$, and $P_{a}$ is any other pressure, say standard atmospheric pressure, then $h^{\prime \prime}-h^{\prime \prime}{ }_{i}$ is the difference in specific enthalpy of saturated ice, under its own equilibrium vapor pressure, between temperatures $T$ and $T_{i}$.

Although measurements of the isopiestic specific heat of ice have been made by several investigators [28-35], only those of Giauque and Stout [34] will be used because it is believed that these are the best available over the range of temperatures of interest here. These measurements were made at standard atmospheric pressure and cover the temperature range 16.43 to $267.77 \mathrm{~K}$. They are in good agreement with the precise measurements of Dickinson and Osborne [30]. Unfortunately, the latter measurements do not extend below $233.15 \mathrm{~K}$.

Fitting the Giauque and Stout data from 169.42 to 267.77 $\mathrm{K}$ to a quadratic equation by the method of least squares with the temperature converted to IPTS-68 and the heat units to joules, yields

$$
c^{\prime \prime} P_{a}=A_{0}+A_{1} T+A_{2} T^{2}
$$

where $c^{\prime \prime}{ }_{P_{a}}$ is the specific heat in $\mathrm{J} / \mathrm{gK}$ at a pressure of one atmosphere. The coefficients are given in table 2 . Integrating eq (19), one obtains

$$
\begin{aligned}
\int_{T_{i}}^{T} c^{\prime \prime}{ }_{P_{a}} d T=A_{0}(T & \left.-T_{i}\right) \\
& +\frac{A_{1}}{2}\left(T^{2}-T_{i}^{2}\right)+\frac{A_{2}}{3}\left(T^{3}-T_{i}^{3}\right) .
\end{aligned}
$$

By letting

$$
\begin{aligned}
\Delta h^{\prime \prime}=\int_{p_{i}}^{P_{a}}\left[v^{\prime \prime}-T\left(\frac{\partial v^{\prime \prime}}{\partial T}\right)_{p_{i}}\right]_{T_{i}} d P & \\
& +\int_{P_{a}}^{P}\left[v^{\prime \prime}-T\left(\frac{\partial v^{\prime \prime}}{\partial T}\right)_{P_{a}}\right]_{T} d P
\end{aligned}
$$

and performing the indicated differentiations and integrations, eq (21) is reduced to the form

$$
\Delta h^{\prime \prime}=B_{0}+B_{1} T^{2}+B_{2} p
$$

where $p$ is the saturation vapor pressure in $\mathrm{Pa}$ at temperature $T, P_{a}=101325 \mathrm{~Pa}$ and $p_{i}=611 \mathrm{~Pa}$. The coefficients are given in table 2. Substitution of eqs (20) and (22) into (18) yields

$h^{\prime \prime}=h_{i}^{\prime \prime}+A_{0}\left(T-T_{i}\right)+\frac{A_{1}}{2}\left(T^{2}-T_{i}{ }^{2}\right)$

$$
+\frac{A_{2}}{3}\left(T^{3}-T_{i}^{3}\right)+\Delta h^{\prime \prime}
$$

A numerical value remains to be assigned to the reference enthalpy $h^{\prime \prime}{ }_{i}$. At any specified temperature $T$, the latent heat of fusion of ice $l^{\prime \prime}$ is given by

$$
l^{\prime \prime}=h^{\prime}-h^{\prime \prime}
$$

where $h^{\prime}$ and $h^{\prime \prime}$ are the specific enthalpies of liquid water and ice, respectively. By adopting the convention $h^{\prime}{ }_{i}=0$ at the ice-point temperature it follows that $l^{\prime \prime}{ }_{i}=-h^{\prime \prime}{ }_{i}$. The choice of this convention will not effect the final results because the arbitrary assignment will cancel out in the computations. Use is now made of the experimentally determined value for the latent heat of fusion of ice at $0{ }^{\circ} \mathrm{C}$ and standard atmospheric pressure recommended by Osborne $[36]^{5}$, namely, $333.535 \mathrm{~J} / \mathrm{g}$. By means of the thermodynamic relationship

$$
\left(\frac{\partial h}{\partial P}\right)_{T}=v-T\left(\frac{d v}{d T}\right)_{P}
$$

the latent heat was adjusted from standard atmospheric pressure $(101325 \mathrm{~Pa})$ to the saturation vapor pressure of ice at 0 ${ }^{\circ} \mathrm{C}$, i.e., $611 \mathrm{~Pa}$, yielding $l^{\prime \prime}{ }_{i}=-h^{\prime \prime}{ }_{i}=333.430 \mathrm{~J} / \mathrm{g}$. Equation (23) therefore becomes

$$
\begin{aligned}
h^{\prime \prime}=-l^{\prime \prime}{ }_{i}+A_{0}\left(T-T_{i}\right)+ & \frac{A_{1}}{2}\left(T^{2}-T_{i}{ }^{2}\right) \\
& +\frac{A_{2}}{3}\left(T^{3}-T_{i}^{3}\right)+\Delta h^{\prime \prime}
\end{aligned}
$$

\subsection{Enthalphy of Water Vapor}

From eqs (3) and (6) it follows that

$$
v=\frac{R T}{p}\left(1+B^{\prime} p+C^{\prime} p^{2}+\cdots\right)
$$

and

$$
\begin{aligned}
\left(\frac{\partial v}{\partial T}\right)_{p}=\frac{R}{p}\left(1+B^{\prime} p\right. & \left.+C^{\prime} p^{2}+\cdots\right) \\
& +\frac{R T}{p}\left(p \frac{\partial B^{\prime}}{\partial T}+p^{2} \frac{\partial C^{\prime}}{\partial T}+\cdots\right)
\end{aligned}
$$

which on substitution into eq (25) yield

$$
\left(\frac{\partial h}{\partial p}\right)_{T}=-R T^{2}\left[\frac{\partial B^{\prime}}{\partial T}+p \frac{\partial C^{\prime}}{\partial T}+\cdots\right] .
$$

Integration with respect to $p$ leads to

$$
h_{p, T}=h_{p_{0}, T}-R T^{2} \frac{\partial B^{\prime}}{\partial T} p-\frac{1}{2} R T^{2} \frac{\partial C^{\prime}}{\partial T} p^{2}-\cdots
$$

${ }^{5}$ The value given by Osborne was converted from international joules to absolute joules by the factor $1.000165 \mathrm{~J}=1 \mathrm{i} . \mathrm{j}$. 
where $h_{p, T}$ is the enthalpy of water vapor at saturation pressure $p$ and temperature $T$ and $h_{p_{0}, T}$ is the ideal-gas (zeropressure) specific enthalpy at the same temperature $T$. The third and higher-order terms will be ignored because their contributions to $h_{p, T}$ are negligible. Thus, by setting

$$
\Delta h=R T^{2} \frac{\partial B^{\prime}}{\partial T} p
$$

the result can be written

$$
h_{p, T}=h_{p_{0}, T}-\Delta h
$$

Friedman and Haar [37] have calculated the ideal-gas (zero-pressure) specific heat $c_{p_{0}} / R$ for water vapor from statistical mechanical considerations over a wide range of temperatures. Their calculated values from 170 to $280 \mathrm{~K}$ were fitted to a polynomial equation by the method of least squares which, after multiplying by $R$, has the form

$$
c_{p_{0}}=D_{0}+D_{1} T+D_{2} T^{2}+D_{3} T^{3}
$$

in units of $\mathrm{J} / \mathrm{gK}$. The coefficients are given in table 2 . Integrating with respect to temperature from the ice point temperature $T_{i}$ to $T$, one gets

$$
h_{p_{0}, T}-h_{p_{0}, T_{i}}=\int_{T_{i}}^{T} c_{p_{0}} d T
$$

which becomes

$$
\begin{aligned}
h_{p_{0}, T}-h_{p_{0}, T_{i}}=D_{0}( & \left.-T_{i}\right)+\frac{D_{1}}{2}\left(T^{2}-T_{i}^{2}\right) \\
+ & \frac{D_{2}}{3}\left(T^{3}-T_{i}^{3}\right)+\frac{D_{3}}{4}\left(T^{4}-T_{i}^{4}\right)
\end{aligned}
$$

where $h_{p_{0}, T}$ and $h_{p_{0}, T_{i}}$ are the ideal-gas (zero-pressure) specific enthalpies of water vapor at temperatures $T$ and $T_{i}$ in units of $\mathrm{J} / \mathrm{g}$.

The ideal gas specific enthalphy $h_{p_{0}, T_{i}}$ is a constant to which a numerical value must be assigned. In order to do so use is made of the latent heat of vaporization $l^{\prime}$ at the ice point. By definition

$$
l^{\prime}=h-h^{\prime} .
$$

It will be recalled that the convention that $h^{\prime}{ }_{i}=0$ at the ice point has already been adopted. Hence at this temperature $h_{i}=l^{\prime}{ }_{i}$, with the result that eq $(32)$ becomes

$$
h_{i}=h_{p_{0}, T_{i}}-\Delta h_{i}
$$

where

$$
\Delta h_{i}=R T_{i}{ }^{2} \frac{\partial B^{\prime}}{\partial T} p_{i}
$$

Replacing $h_{i}$ by $l^{\prime}{ }_{i}$ in eq (37), one obtains

$$
h_{p_{0}, T_{i}}=l^{\prime}{ }_{i}+\Delta h_{i}
$$

Substituting eq (39) into eq (35) gives rise to an expression for the ideal-gas specific enthalpy of water vapor, that is,

$$
\begin{aligned}
h_{p_{0}, T}=l^{\prime}{ }_{i}+\Delta h_{i} & +D_{0}\left(T-T_{i}\right)+\frac{D_{1}}{2}\left(T^{2}-T_{i}{ }^{2}\right) \\
& +\frac{D_{2}}{3}\left(T^{3}-T_{i}^{3}\right)+\frac{D_{3}}{4}\left(T^{4}-T_{i}^{4}\right) .
\end{aligned}
$$

Now by inserting eq (40) into (32) the real-gas specific enthalpy of saturated water vapor ensu-, namely,

$$
\begin{aligned}
h & =h_{p, T}=l^{\prime}{ }_{i}+\Delta h_{i}-\Delta h+D_{0}\left(T-T_{i}\right) \\
& +\frac{D_{1}}{2}\left(T^{2}-T_{i}^{2}\right)+\frac{D_{2}}{3}\left(T^{3}-T_{i}^{3}\right)+\frac{D_{3}}{4}\left(T^{4}-T_{i}^{4}\right)
\end{aligned}
$$

To calculate $l^{\prime}{ }_{i}$, use is made of an approach due to Osborne [38] which starts with the definition of an experimentally measured calorimetric quantity $\gamma$

$$
l^{\prime}=\gamma-\delta
$$

$\gamma$ has been quite accurately measured [38-41]. $\delta$ is given by [38]

$$
\delta=\left(\frac{v^{\prime}}{v-v^{\prime}}\right) l^{\prime}=v^{\prime} T \frac{d p}{d T}
$$

TABLE 2. Coefficients to equations

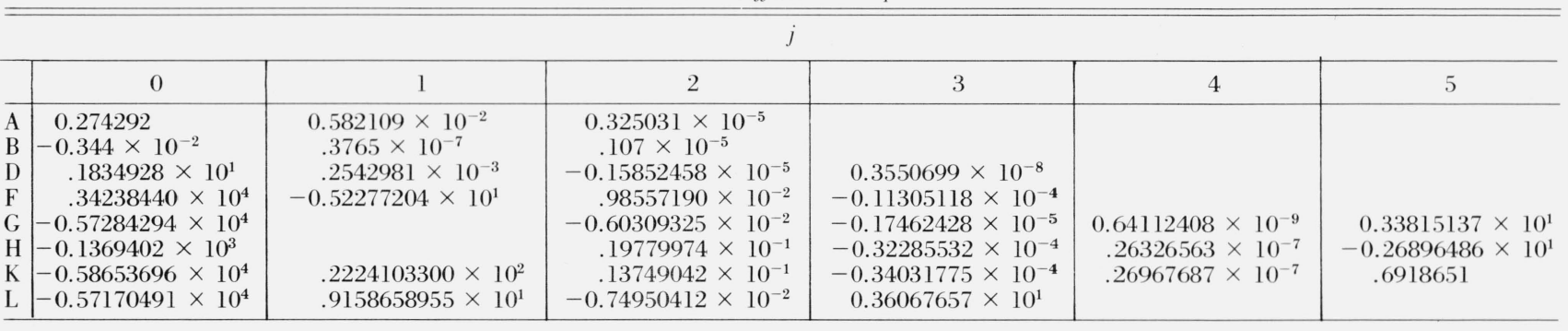


where $v$ and $v^{\prime}$ are the specific volumes of saturated vapor and water, respectively, and $d p / d T$ is the temperature derivative of the vapor pressure of liquid water. The quantity $\gamma$ is represented with high precision from 273.15 to $423.15 \mathrm{~K}$ in units of $\mathrm{J} / \mathrm{g}$ by the following polynomial equation [3]

$$
\gamma=F_{0}+F_{1} T+F_{2} T^{2}+F_{3} T^{3} .
$$

The coefficients are given in table 2 . At $T=273.15 \mathrm{~K}, \gamma_{i}=$ $2500.8384 \mathrm{~J} / \mathrm{g}$. The quantity $\delta_{i}$, at $T=273.15 \mathrm{~K}$, using $v^{\prime}=$ $1.00016 \mathrm{~cm}^{3} / \mathrm{g}[42]$ and $d p / d T=44.4 \mathrm{~Pa} / \mathrm{K}[3]$, is 0.0121 $\mathrm{J} / \mathrm{g}$. Therefore $l^{\prime}{ }_{i}=2500.8263 \mathrm{~J} / \mathrm{g}$. By appropriate substitutions into eq (38) one obtains $\Delta h_{i}=0.2365 \mathrm{~J} / \mathrm{g}$.

\subsection{Latent Heat of Sublimation}

Substitution of eqs (26) and (41) into (2) gives rise to the following equation for the latent heat of sublimation:

$$
\begin{aligned}
l= & {\left[\left(\gamma_{i}-\delta_{i}+\Delta h_{i}+l^{\prime}{ }_{i}\right)-\left(D_{0}-A_{0}\right) T_{i}\right.} \\
& \left.-\frac{1}{2}\left(D_{1}-A_{1}\right) T_{i}^{2}-\frac{1}{3}\left(D_{2}-A_{2}\right) T_{i}^{3}-\frac{1}{4} D_{3} T_{i}^{4}\right] \\
& +\left(D_{0}-A_{0}\right) T+\frac{1}{2}\left(D_{1}-A_{1}\right) T^{2}+\frac{1}{3}\left(D_{2}-A_{2}\right) T^{3} \\
& +\frac{1}{4} D_{3} T^{4}-\Delta h-\Delta h^{\prime \prime} .
\end{aligned}
$$

\subsection{Vapor Pressure}

Combining eqs (5) and (45), selecting the temperature $T_{t}$ and vapor pressure $p_{t}$ at the triple point as the lower limits of integration, taking any temperature $T$ and corresponding vapor pressure $p$ as the upper limits, and performing some simple mathematical manipulations, one obtains

$$
\begin{aligned}
& \int_{p_{t}}^{p} d(\ln p) \\
& =\sum_{j=0}^{4} G_{j}\left(T^{j-1}-T_{t}^{j-1}\right)+G_{5} \ln \left(\frac{T}{T_{t}}\right) \\
& \quad-\int_{T_{t}}^{T} \frac{\Delta h}{R T^{2}} d T-\int_{T_{t}}^{T} \frac{\Delta h^{\prime \prime}}{R T^{2}} d T \\
& \quad-\int_{T_{t}}^{T} \frac{l}{R T^{2}}\left(\frac{Z-1}{Z}\right) d T+\int_{T_{t}}^{T} \frac{l}{Z R T^{2}}\left(\frac{v^{\prime \prime}}{v}\right) d T
\end{aligned}
$$

$$
\begin{aligned}
& \left.-\frac{1}{3}\left(D_{2}-A_{2}\right) T_{i}^{3}-\frac{1}{4} D_{3} T_{i}^{4}\right] \\
G_{2}= & \frac{D_{1}-A_{1}}{2 R} \\
G_{3}= & \frac{D_{2}-A_{2}}{6 R} \\
G_{4}= & \frac{D_{3}}{12 R} \\
\text { and } G_{5}= & \frac{D_{0}-A_{0}}{R}
\end{aligned}
$$

The coefficients are given in table 2 .

The first two terms on the right-hand side of eq (46) provide the major contribution to the vapor pressure; the integrals are small corrections which account, in part, for the deviation of water vapor from ideal gas behavior. These have been left in integral form because each is a function of $p$ as well as $T$.

The absolute temperature assigned to the triple point on IPTS-68 is $273.16 \mathrm{~K}$. The corresponding vapor pressure is $611.657 \mathrm{~Pa}$, the definitive value measured by Guildner, Johnson, and Jones [4]. The specific gas constant for water, $R$ $=0.461520 \mathrm{~J} / \mathrm{g} \mathrm{K}$, was derived from the CODATA recommended value of $8.31441 \mathrm{~J} / \mathrm{mol} \mathrm{K}$ for the universal gas constant [43], and $18.015227 \mathrm{~g}$ for the molar mass of naturally occurring water vapor on the unified carbon- 12 scale. $^{6}$

Because eq (46) is implicit in $p$ it had to be solved by iteration. Each of the integrals on the right-hand side was evaluated at intervals of 0.25 kelvins by means of the trapezoidal rule [47]. Iteration at each interval was terminated when successive values of $p$ differed by less than $0.1 \mathrm{ppm}$. The magnitudes of the terms in eq (46) are shown in skeleton form in table 3 . The magnitudes of the integral terms are equivalent to the relative contributions they make to the vapor pressure. The sum of the integrals increases from zero at the triple point to -0.000389 at $-100{ }^{\circ} \mathrm{C}$. Neglecting the integrals, therefore, would introduce an error of up to 389 $\mathrm{ppm}$ in the vapor pressure. The sums of the integrals, at intervals of 2 kelvins, were fitted by the method of least squares to the equation

$$
\sum \text { integrals }=\sum_{j=0}^{4} H_{j}\left(T^{j-1}-T_{t}^{j-1}\right)+H_{5} \ln \left(\frac{T}{T_{t}}\right)
$$

with a residual standard deviation [48] of $0.7 \times 10^{-6}$. The coefficients are given in table 2 . Substituting eq (52) into (46), integrating the left-hand side, and combining terms,

where $G_{0}=-\frac{1}{R}\left[\left(\gamma_{i}-\delta_{i}+\Delta h_{i}+l^{\prime \prime}{ }_{i}\right)\right.$

$$
-\left(D_{0}-A_{0}\right) T_{i}-\frac{1}{2}\left(D_{1}-A_{1}\right) T_{i}^{2}
$$

\footnotetext{
${ }^{6}$ According to Eisenberg and Kauzman [44], who quote Shatenshtein et al. [45], the isotopic content of naturally occurring water depends on its origin. Within the limits of variation normall encountered the isotopes are $\mathrm{H}_{2}{ }^{16} \mathrm{O}, \mathrm{H}_{2}{ }^{17} \mathrm{O}, \mathrm{H}_{2}{ }^{18} \mathrm{O}$ and $\mathrm{HDO}$ and the abundances are 99.73,0.04. 0.20 , and 0.03 percent, respectively. Combining these abundances with the relative atomic masses of 0.20 , and 0.03 percent, respectively. Combining these abundances with the relative atomic masses of
the appropriate nuclides, recommended by the Commission on Atomic Weights [46], yielded the value 18.015277 grams for the molecular weight of naturally occurring water.
} 


\begin{tabular}{|c|c|c|c|c|c|c|c|c|}
\hline$t$ & $\sum_{j=0}^{4} G_{j}\left(T^{j-1}-\mathrm{T}_{t}^{j-1}\right)+G_{5} \ln \left(\frac{T}{T_{t}}\right)$ & $\int_{T_{t}}^{T} \frac{\Delta h}{R T^{2}} d T$ & $\int_{T_{t}}^{T} \frac{\Delta h^{\prime \prime}}{R T^{2}} d T$ & $\int_{T_{t}}^{T} \frac{l}{R T^{2}}\left(\frac{Z-1}{Z}\right) d T$ & $\int_{T_{t}}^{T} \frac{l}{Z R T^{2}}\left(\frac{v^{\prime \prime}}{v}\right) d T$ & $\sum$ integrals & $\ln \left(\frac{p}{p_{t}}\right)$ & $p$ \\
\hline${ }^{\circ} \mathrm{C}$ & & & & & & & & $\mathrm{Pa}$ \\
\hline $\begin{array}{l}0.01 \\
0 \\
-10 \\
-20 \\
-30 \\
-40 \\
-50 \\
-60 \\
-70 \\
-80 \\
-90 \\
-100\end{array}$ & $\begin{array}{c}-0.0000000 \\
-0.0008231 \\
-0.8556016 \\
-1.7784775 \\
-2.7776170 \\
-3.8625689 \\
-5.0445714 \\
-6.3369461 \\
-7.7556071 \\
-9.3197265 \\
-11.0526186 \\
-12.9829316\end{array}$ & $\begin{array}{l}-0.0000000 \\
-0.0000000 \\
-0.0000515 \\
-0.0000786 \\
-0.0000920 \\
-0.0000982 \\
-0.0001008 \\
-0.0001018 \\
-0.0001022 \\
-0.0001023 \\
-0.0001024 \\
-0.0001024\end{array}$ & $\begin{array}{r}0.0000000 \\
.0000000 \\
.0000001 \\
.0000003 \\
.0000007 \\
.0000012 \\
.0000018 \\
.0000026 \\
.0000035 \\
.0000045 \\
.0000058 \\
.0000074\end{array}$ & $\begin{array}{l}0.0000000 \\
.0000001 \\
.0002348 \\
.0003614 \\
.0004258 \\
.0004565 \\
.0004701 \\
.0004756 \\
.0004776 \\
.0004783 \\
.0004784 \\
.0004785\end{array}$ & $\begin{array}{l}-0.0000000 \\
-0.0000000 \\
-0.0000031 \\
-0.0000045 \\
-0.0000051 \\
-0.0000054 \\
-0.0000055 \\
-0.0000055 \\
-0.0000055 \\
-0.0000055 \\
-0.0000055 \\
-0.0000055\end{array}$ & $\begin{array}{l}-0.0000000 \\
-0.0000001 \\
-0.0001864 \\
-0.0002877 \\
-0.0003397 \\
-0.0003649 \\
-0.0003766 \\
-0.0003818 \\
-0.0003844 \\
-0.0003860 \\
-0.0003874 \\
-0.0003890\end{array}$ & $\begin{array}{r}-0.0000000 \\
-0.0008232 \\
-0.8557880 \\
-1.7787652 \\
-2.7779567 \\
-3.8629338 \\
-5.0449480 \\
-6.3373279 \\
-7.7559915 \\
-9.3201125 \\
-11.0530060 \\
-12.9833206\end{array}$ & $\begin{array}{c}611.657 \\
611.154 \\
259.923 \\
103.276 \\
38.0239 \\
12.8486 \\
3.94017 \\
1.08204 \\
0.261893 \\
.0548068 \\
.00968832 \\
.00140580\end{array}$ \\
\hline
\end{tabular}

$\sum$ integrals $=-\int_{T_{t}}^{T} \frac{\Delta h}{R T^{2}} d T-\int_{T_{t}}^{T} \frac{\Delta h^{\prime \prime}}{R T^{2}} d T-\int_{T_{t}}^{T} \frac{l}{R T^{2}}\left(\frac{Z-1}{Z}\right) d T+\int_{T_{t}}^{T} \frac{l}{Z R T^{2}}\left(\frac{v^{\prime \prime}}{v}\right) d T$

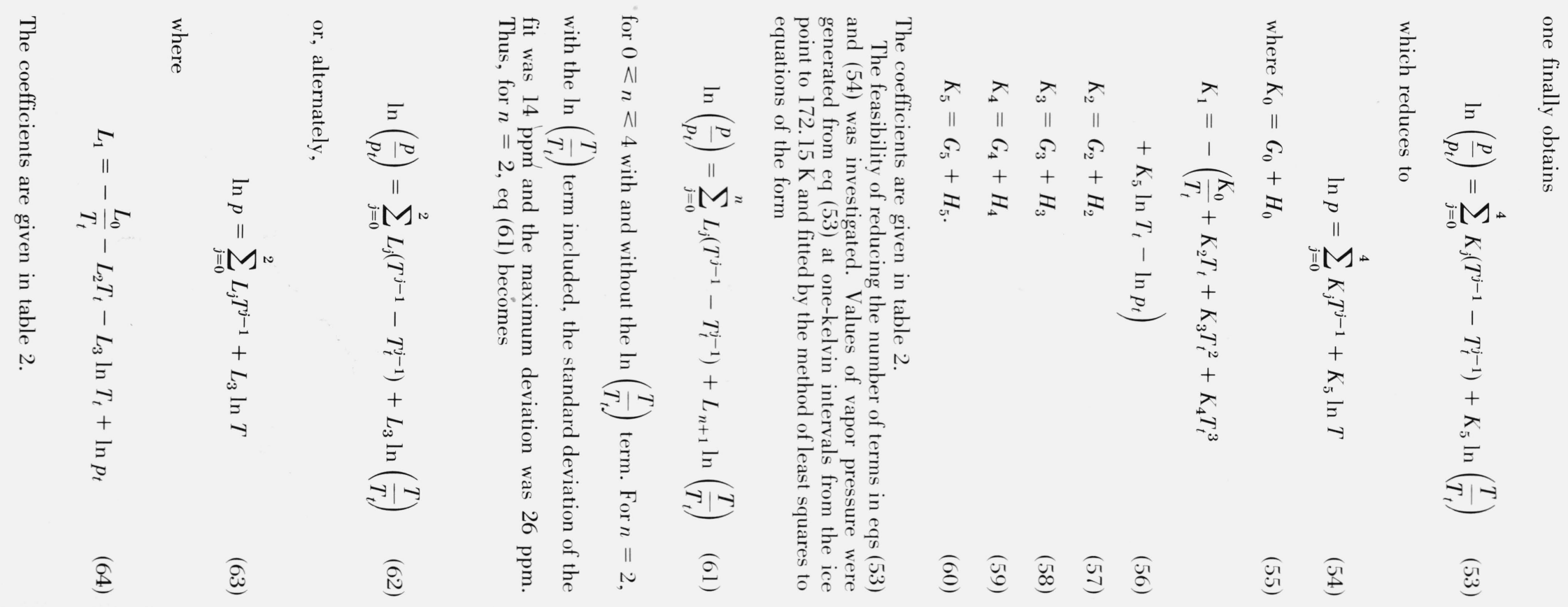




\section{Error Analysis}

It is of interest to assign reasonable bounds of uncertainty to the independent variables and constants and then calculate the effect of these uncertainties on $p$. Start with eq (5) and recall that

$$
\begin{gathered}
Z=1+B^{\prime} p \\
v=\frac{Z R T}{p} \\
v^{\prime \prime}=v_{P_{a}, T_{i}}^{\prime \prime}\left[1+3 \int_{T_{i}}^{T} \alpha_{P_{a}} d T\right]\left[1-k\left(p-P_{a}\right)\right] \\
l=\int_{T_{i}}^{T} c_{p_{o}} d T+\gamma_{i}-\delta_{i}+\Delta h_{i}-\Delta h \\
-\int_{T_{i}}^{T} c^{\prime \prime}{ }_{P_{a}} d T-\Delta h^{\prime \prime}+l^{\prime \prime}{ }_{i}
\end{gathered}
$$

where

$$
\Delta h=R T^{2} \frac{\partial B^{\prime}}{\partial T} p
$$

and

$$
\begin{aligned}
\Delta h^{\prime \prime}=\int_{p_{i}}^{P_{a}}\left[v^{\prime \prime}-T\left(\frac{\partial v^{\prime \prime}}{\partial T}\right)_{p_{i}}\right]_{T_{i}} d P \\
+\int_{P_{a}}^{p}\left[v^{\prime \prime}-T\left(\frac{\partial v^{\prime \prime}}{\partial T}\right)_{P_{a}}\right]_{T} d P
\end{aligned}
$$

Substituting the above equations into eq (5) converts the latter into a functional relationship of independent variables and constants. The vapor pressure is calculated by iteration and numerical integration, as previously described. The calculation then is repeated with each variable and constant separately augmented by its appropriate estimated error.

The absolute temperature $T$ enters into eq (5) as the independent variable so that it is subject neither to experimental nor scale error. However, experimental and scale errors in the temperature affect the uncertainties in the independent variables; therefore, these temperature errors are contained in the estimated errors of the independent variables. Since $T_{t}$ is assigned values on IPTS-68, it will be assumed that its estimated uncertainty is zero.

The estimated error in the specific gas constant for water vapor $R$ arises from the assigned (three standard deviations) uncertainty [43] in the molar gas constant of $78 \times 10^{-5} \mathrm{~J} / \mathrm{mol}$ $\mathrm{K}$ and from a calculated (three standard deviations) uncertainty in the molecular weight of naturally occurring water of $9 \times 10^{-5} \mathrm{~g} / \mathrm{mol}$ based on the assigned uncertainties [46] in the relative atomic masses of the pertinent nuclides. The resultant estimated error (three standard deviations) in $R$ is $45 \times 10^{-6} \mathrm{~J} / \mathrm{g} \mathrm{K}(94 \mathrm{ppm})$.

There are no experimental data below $273.15 \mathrm{~K}$ on which to base an estimate of the uncertainty in the virial coefficient $\mathrm{B}^{\prime}$ nor in the derivative $d B^{\prime} / d T$. Therefore, four sets of extrapolated virial coefficients were calculated, using the empirical equations of Goff and Gratch [12-14], Keyes [15, 16], and Juza as given by Bain [17], and then differences were obtained from the latest Keyes values [16]. The estimated uncertainty was set at thrice the maximum difference. This uncertainty in $B^{\prime}$ contributed to a corresponding uncertainty in $d B^{\prime} / d T$.

$P_{a}$ is standard atmospheric pressure. Because this is an assigned value it will be assumed that its uncertainty is zero.

Guildner, Johnson, and Jones [4] have assigned an estimated uncertainty (three standard deviations plus systematic errors) of $0.010 \mathrm{~Pa}(16 \mathrm{ppm})$ to their measured value of the vapor pressure at the triple point $p_{t}$. Their estimated uncertainty will be used here.

According to Ginnings and Corruccini [19], the combined random and systematic uncertainty in their determination of the density of ice at $0{ }^{\circ} \mathrm{C}$ and 1 atmosphere is $0.00005 \mathrm{~g} / \mathrm{ml}$. This value was converted to $0.00006 \mathrm{~cm}^{3} / \mathrm{g}$ and the latter used as the estimated uncertainty in the specific volume of ice $v^{\prime \prime} P_{a}, T_{i}$. The estimated uncertainty in the coefficient $\alpha_{P_{a}}$ will be taken as three times the standard deviation of the fit [48] as given by eq (10), that is, $0.50 \times 10^{-5} \mathrm{~cm} / \mathrm{cm} \mathrm{K}$. Leadbetter [27] has ascribed an uncertainty of 5 percent to his values of the adiabatic compressibility of ice, namely 0.6 $\mathrm{cm}^{3} / \mathrm{cm}^{3} \mathrm{~Pa}$. The same uncertainty is therefore used for the isothermal compressibility $k$, since the latter is derived from Leadbetter's values.

Friedman and Haar [37] have computed $c_{p_{0}} / R$ to six significant figures. However, they did not give an estimate of the uncertainty in their calculated values. An error of 100 ppm therefore was assigned to $c_{p_{0}} / R$. Combining this error along with $99 \mathrm{ppm}$ for the estimated uncertainty in $R$ and 9 ppm which represents three times the residual standard deviation of the fit of eq (33) resulted in an estimated error of $140 \mathrm{ppm}$ in $c_{\boldsymbol{p}_{0}}$, i.e., $0.26 \times 10^{-3} \mathrm{~J} / \mathrm{g} \mathrm{K}$.

In the absence of any other criteria for estimating the uncertainty in $c^{\prime \prime}{ }_{P_{a}}$, a value of $0.0103 \mathrm{~J} / \mathrm{g} \mathrm{K}$ was selected which equals three times the standard deviation of the fit of eq (19), $0.0099 \mathrm{~J} / \mathrm{g} \mathrm{K}$, plus an estimated error of $0.0004 \mathrm{~J} / \mathrm{g}$ $\mathrm{K}$ due to ambiguities in the temperature scale employed by Giauque and Stout.

The estimated error in $\gamma_{i}$ was taken as $0.45 \mathrm{~J} / \mathrm{g}$ which is three times the standard deviation of the fit of eq (44). The uncertainty in $\delta_{i}$ was conservatively estimated at less than one percent, that is, less than $0.0001 \mathrm{~J} / \mathrm{g}$. Osborne [36] has estimated that the random and systematic error in $l_{i}^{\prime \prime}$ was 0.2 $\mathrm{J} / \mathrm{g}$ and his value, therefore, was used here.

The quantity $\Delta h^{\prime \prime}$ varies from zero at $0{ }^{\circ} \mathrm{C}$ to about -0.002 $\mathrm{J} / \mathrm{g}$ at $-100{ }^{\circ} \mathrm{C}$. Since it is small compared to $l(\sim 2830 \mathrm{~J} / \mathrm{g})$, its functional dependence on other parameters will be ignored. The uncertainty in $\Delta h^{\prime \prime}$ was estimated at less than $0.0001 \mathrm{~J} / \mathrm{g}$.

A summary of the individual estimated errors contributing to the total error in the predicted vapor pressure is given in table 4 . The corresponding uncertainty in $p$ due to each of the enumerated errors is shown in table 5. The square root of the sum of the squares of the individual errors was used as the best estimate of the overall maximum error in $p$ [49]. As the temperature decreases from the triple point to $-100{ }^{\circ} \mathrm{C}$, the estimated relative error in $p$ increases from $16 \mathrm{ppm}$ to 0.5 percent. 
TABLE 4. Summary of estimated errors in variables and constants

\begin{tabular}{|c|c|c|c|c|c|c|c|c|c|c|c|c|}
\hline \multirow{3}{*}{$\frac{c \text { Temperature }}{{ }^{t}}$} & & & \multicolumn{10}{|c|}{ Parameter } \\
\hline & \multicolumn{2}{|c|}{$R$} & \multicolumn{2}{|c|}{$B^{\prime}$} & \multicolumn{2}{|l|}{$P_{t}$} & \multicolumn{2}{|c|}{$v^{\prime \prime}{ }_{P_{a}, T_{i}}$} & \multicolumn{2}{|c|}{$k$} & \multicolumn{2}{|c|}{$c_{p_{o}}$} \\
\hline & $\begin{array}{l}\text { Magnitude } \\
\text { J/gK }\end{array}$ & $\begin{array}{l}\text { Error } \\
\mathrm{J} / \mathrm{gK}\end{array}$ & $\begin{array}{l}\text { Magnitude } \\
1 / \mathrm{Pa}\end{array}$ & $\begin{array}{l}\text { Error } \\
1 / \mathrm{Pa}\end{array}$ & $\begin{array}{c}\text { Magnitude } \\
\mathrm{Pa}\end{array}$ & $\begin{array}{c}\text { Error } \\
\mathrm{Pa}\end{array}$ & $\begin{array}{l}\text { Magnitude } \\
\mathrm{cm}^{3} / \mathrm{g}\end{array}$ & $\begin{array}{l}\text { Error } \\
\mathrm{cm}^{3} / \mathrm{g}\end{array}$ & $\begin{array}{l}\text { Magnitude } \\
\mathrm{cm}^{3} / \mathrm{cm}^{3} \mathrm{~Pa}\end{array}$ & $\begin{array}{c}\begin{array}{c}\text { Error } \\
\mathrm{cm}^{3} / \mathrm{cm}^{3} \mathrm{~Pa}\end{array} \\
\end{array}$ & $\underset{\text { J/gK }}{\text { Magnitude }}$ & $\begin{array}{l}\text { Error } \\
\mathrm{J} / \mathrm{gK}\end{array}$ \\
\hline 0.01 & 0.461520 & 0.000045 & $-0.6151 \times 10^{-6}$ & $0.6303 \times 10^{-6}$ & 611.657 & 0.010 & 1.09089 & 0.00006 & $0.13 \times 10^{-9}$ & $0.6 \times 10^{-11}$ & 1.85848 & 0.00026 \\
\hline 0 & .461520 & .000045 & $-0.6151 \times 10^{-6}$ & $.6303 \times 10^{-6}$ & 611.657 & .010 & 1.09089 & .00006 & $.13 \times 10^{-9}$ & $.6 \times 10^{-11}$ & 1.85848 & .00026 \\
\hline-10 & .461520 & .000045 & $-0.7420 \times 10^{-6}$ & $.9333 \times 10^{-6}$ & 611.657 & .010 & 1.09089 & .00006 & $.13 \times 10^{-9}$ & $.6 \times 10^{-11}$ & 1.85677 & .00026 \\
\hline-20 & .461520 & .000045 & $-0.9036 \times 10^{-6}$ & $.1432 \times 10^{-5}$ & 611.657 & .010 & 1.09089 & .00006 & $.13 \times 10^{-9}$ & $.6 \times 10^{-11}$ & 1.85532 & .00026 \\
\hline-30 & .461520 & .000045 & $-0.1112 \times 10^{-5}$ & $.2278 \times 10^{-5}$ & 611.657 & .010 & 1.09089 & .00006 & $.13 \times 10^{-9}$ & $.6 \times 10^{-11}$ & 1.85408 & .00026 \\
\hline-40 & .461520 & .000045 & $-0.1383 \times 10^{-5}$ & $.3755 \times 10^{-5}$ & 611.657 & .010 & 1.09089 & .00006 & $.13 \times 10^{-9}$ & $.6 \times 10^{-11}$ & 1.85305 & .00026 \\
\hline-50 & .461520 & .000045 & $-0.1741 \times 10^{-5}$ & $.6414 \times 10^{-5}$ & 611.657 & .010 & 1.09089 & .00006 & $.13 \times 10^{-9}$ & $.6 \times 10^{-11}$ & 1.85219 & .00026 \\
\hline-60 & .461520 & .000045 & $-0.2219 \times 10^{-5}$ & $.1135 \times 10^{-4}$ & 611.657 & .010 & 1.09089 & .00006 & $.13 \times 10^{-9}$ & $.6 \times 10^{-11}$ & 1.85149 & .00026 \\
\hline-70 & .461520 & .000045 & $-0.2866 \times 10^{-5}$ & $.2083 \times 10^{-4}$ & 611.657 & .010 & 1.09089 & .00006 & $.13 \times 10^{-9}$ & $.6 \times 10^{-11}$ & 1.85093 & .00026 \\
\hline-80 & .461520 & .000045 & $-0.3753 \times 10^{-5}$ & $.3961 \times 10^{-4}$ & 611.657 & .010 & 1.09089 & .00006 & $.13 \times 10^{-9}$ & $.6 \times 10^{-11}$ & 1.85049 & .00026 \\
\hline-90 & .461520 & .000045 & $-0.4987 \times 10^{-5}$ & $.7806 \times 10^{-4}$ & 611.657 & .010 & 1.09089 & .00006 & $.13 \times 10^{-9}$ & $.6 \times 10^{-11}$ & 1.85014 & .00026 \\
\hline-100 & .461520 & .000045 & $-0.6728 \times 10^{-5}$ & $.1594 \times 10^{-3}$ & 611.657 & .010 & 1.09089 & .00006 & $.13 \times 10^{-9}$ & $.6 \times 10^{-11}$ & 1.84987 & .00026 \\
\hline
\end{tabular}

TABLE 4. Summary of estimated errors in variables and constants - continued

\begin{tabular}{|c|c|c|c|c|c|c|c|c|c|c|c|c|}
\hline \multirow{2}{*}{$\frac{\text { Temperature }}{t}$} & & & \multicolumn{10}{|c|}{ Parameter } \\
\hline & \multicolumn{2}{|c|}{$c^{\prime \prime} P_{a}$} & \multicolumn{2}{|c|}{$\gamma_{i}$} & \multicolumn{2}{|c|}{$\delta_{i}$} & \multicolumn{2}{|c|}{$l^{\prime \prime}{ }_{i}$} & \multicolumn{2}{|c|}{$\Delta h^{\prime \prime}$} & \multicolumn{2}{|c|}{$\alpha_{P_{a}}$} \\
\hline${ }^{\circ} \mathrm{C}$ & $\begin{array}{l}\text { Magnitude } \\
\mathrm{J} / \mathrm{gK}\end{array}$ & $\begin{array}{l}\text { Error } \\
\mathrm{J} / \mathrm{gK}\end{array}$ & $\underset{\mathrm{J} / \mathrm{g}}{\text { Magnitude }}$ & $\begin{array}{c}\text { Error } \\
\mathrm{J} / \mathrm{g}\end{array}$ & $\underset{\mathrm{J} / \mathrm{g}}{\text { Magnitude }}$ & $\begin{array}{c}\text { Error } \\
\mathrm{J} / \mathrm{g}\end{array}$ & $\underset{\mathrm{J} / \mathrm{g}}{\text { Magnitude }}$ & $\begin{array}{c}\text { Error } \\
\mathrm{J} / \mathrm{g}\end{array}$ & $\underset{\mathrm{J} / \mathrm{g}}{\text { Magnitude }}$ & $\begin{array}{c}\text { Error } \\
\mathrm{J} / \mathrm{g}\end{array}$ & $\begin{array}{c}\text { Magnitude } \\
\mathrm{cm} / \mathrm{cm} \mathrm{K}\end{array}$ & $\begin{array}{c}\text { Error } \\
\mathrm{cm} / \mathrm{cm} \mathrm{K}\end{array}$ \\
\hline 0.01 & 2.1069 & 0.0103 & 2800.84 & 0.45 & 0.0121 & 0.0001 & 333.43 & 0.2 & -0.0000 & 0.0001 & $0.544 \times 10^{-4}$ & $0.50 \times 10^{-5}$ \\
\hline 0 & 2.1068 & 0.0103 & 2800.84 & 0.45 & 0.0121 & 0.0001 & 333.43 & 0.2 & -0.0000 & 0.0001 & $0.544 \times 10^{-4}$ & $0.50 \times 10^{-5}$ \\
\hline-10 & 2.0312 & 0.0103 & 2800.84 & 0.45 & 0.0121 & 0.0001 & 333.43 & 0.2 & -0.0006 & 0.0001 & $0.521 \times 10^{-4}$ & $0.50 \times 10^{-5}$ \\
\hline-20 & 1.9562 & 0.0103 & 2800.84 & 0.45 & 0.0121 & 0.0001 & 333.43 & 0.2 & -0.0009 & 0.0001 & $0.499 \times 10^{-4}$ & $0.50 \times 10^{-5}$ \\
\hline-30 & 1.8818 & 0.0103 & 2800.84 & 0.45 & 0.0121 & 0.0001 & 333.43 & 0.2 & -0.0012 & 0.0001 & $0.476 \times 10^{-4}$ & $0.50 \times 10^{-5}$ \\
\hline-40 & 1.8082 & 0.0103 & 2800.84 & 0.45 & 0.0121 & 0.0001 & 333.43 & 0.2 & -0.0014 & 0.0001 & $0.453 \times 10^{-4}$ & $0.50 \times 10^{-5}$ \\
\hline-50 & 1.7351 & 0.0103 & 2800.84 & 0.45 & 0.0121 & 0.0001 & 333.43 & 0.2 & -0.0016 & 0.0001 & $0.430 \times 10^{-4}$ & $0.50 \times 10^{-5}$ \\
\hline-60 & 1.6627 & 0.0103 & 2800.84 & 0.45 & 0.0121 & 0.0001 & 333.43 & 0.2 & -0.0017 & 0.0001 & $0.408 \times 10^{-4}$ & $0.50 \times 10^{-5}$ \\
\hline-70 & 1.5910 & 0.0103 & 2800.84 & 0.45 & 0.0121 & 0.0001 & 333.43 & 0.2 & -0.0019 & 0.0001 & $0.385 \times 10^{-4}$ & $0.50 \times 10^{-5}$ \\
\hline-80 & 1.5199 & 0.0103 & 2800.84 & 0.45 & 0.0121 & 0.0001 & 333.43 & 0.2 & -0.0020 & 0.0001 & $0.362 \times 10^{-4}$ & $0.50 \times 10^{-5}$ \\
\hline-90 & 1.4494 & 0.0103 & 2800.84 & 0.45 & 0.0121 & 0.0001 & 333.43 & 0.2 & -0.0022 & 0.0001 & $0.340 \times 10^{-4}$ & $0.50 \times 10^{-5}$ \\
\hline-100 & 1.3797 & 0.0103 & 2800.84 & 0.45 & 0.0121 & 0.0001 & 333.43 & 0.2 & -0.0023 & 0.0001 & $0.317 \times 10^{-4}$ & $0.50 \times 10^{-5}$ \\
\hline
\end{tabular}


TABLE 5. Summary of equivalent errors in vapor pressure due to estimated errors in variables and constants

\begin{tabular}{|c|c|c|c|c|c|c|c|c|c|c|c|c|c|}
\hline \multirow{2}{*}{$\frac{\text { Temperature }}{t}$} & \multicolumn{12}{|c|}{ Parameter } & \multirow{2}{*}{$\begin{array}{c}\text { Estimated } \\
\text { Overall } \\
\text { Error }^{a}\end{array}$} \\
\hline & $R$ & $B^{\prime}$ & $p_{t}$ & $v^{\prime \prime}{ }_{P_{a}, T_{i}}$ & $k$ & $c_{\boldsymbol{p}_{o}}$ & $c^{\prime \prime} P_{a}$ & $\gamma_{i}$ & $\delta_{i}$ & $l^{\prime \prime}{ }_{i}$ & $\Delta h^{\prime \prime}$ & $\alpha_{P_{a}}$ & \\
\hline${ }^{\circ} \mathrm{C}$ & \multicolumn{12}{|c|}{ Estimated error in vapor pressure due to estimated error in indicated parameter, ppm } & ppm \\
\hline 0.01 & 0 & 0 & 16 & $<1$ & $<1$ & 0 & 0 & 0 & $<1$ & 0 & $<1$ & $<1$ & 16 \\
\hline 0 & 0 & 0 & 16 & $<1$ & $<1$ & 0 & 0 & 0 & $<1$ & 0 & $<1$ & $<1$ & 16 \\
\hline-10 & 83 & 532 & 16 & $<1$ & $<1$ & 0 & 15 & 135 & $<1$ & 60 & $<1$ & $<1$ & 559 \\
\hline-20 & 173 & 950 & 16 & $<1$ & $<1$ & 1 & 66 & 282 & $<1$ & 125 & $<1$ & $<1$ & 1016 \\
\hline-30 & 270 & 1289 & 16 & $<1$ & $<1$ & 3 & 157 & 440 & $<1$ & 195 & $<1$ & $<1$ & 1411 \\
\hline-40 & 376 & 1580 & 16 & $<1$ & $<1$ & 7 & 295 & 612 & $<1$ & 272 & $<1$ & $<1$ & 1781 \\
\hline-50 & 491 & 1845 & 16 & $<1$ & $<1$ & 12 & 488 & 799 & $<1$ & 355 & $<1$ & $<1$ & 2156 \\
\hline-60 & 618 & 2101 & 16 & $<1$ & $<1$ & 18 & 746 & 1004 & $<1$ & 436 & $<1$ & $<1$ & 2561 \\
\hline-70 & 756 & 2363 & 16 & $<1$ & $<1$ & 27 & 1081 & 1229 & $<1$ & 546 & $<1$ & $<1$ & 3022 \\
\hline-80 & 909 & 2641 & 16 & $<1$ & $<1$ & 38 & 1508 & 1477 & $<1$ & 656 & $<1$ & $<1$ & 3562 \\
\hline-90 & 1078 & 2943 & 16 & $<1$ & $<1$ & 52 & 2043 & 1752 & $<1$ & 778 & $<1$ & $<1$ & 4064 \\
\hline-100 & 1278 & 3279 & 16 & $<1$ & $<1$ & 72 & 2708 & 2055 & $<1$ & 912 & $<1$ & $<1$ & 4978 \\
\hline
\end{tabular}

${ }^{a}$ Square root of the sum of the squares of the estimated errors contributed by each parameter.

\section{Comparisons}

The first experimental values of the vapor pressure of ice were reported by Regnault [50] in 1847. Subsequently, measurements were made by Fischer [51], Juhlin [52], and Marvin [53]. In 1909, Scheel and Heuse [54] at the Physikalisch-Technische Reichsanstalt (PTR) published the results of their work which superseded all earlier determinations for range, precision and accuracy. Using a Rayleigh inclined manometer and a platinum resistance thermometer they measured the vapor pressure from 0 to $-67^{\circ} \mathrm{C}$. In a second paper [55] they suggested that temperatures interpolated from the Callendar formula would be more in accord with the thermodynamic scale than the temperatures given in their first paper. In 1919, the PTR issued revised values of the Scheel and Heuse measurements [56]. Although not explicitly stated, these new values appear to have been based on the use of the Callendar formula for interpolating temperature measurements with platinum resistance thermometers.

Weber [57] in 1915, employing both a hot-wire manometer and a Knudsen radiometer, made measurements from -22 to $-98{ }^{\circ} \mathrm{C}$. A limited number of determinations were made by Nernst [58] in 1909 and by Drucker, Jimeno, and Kangro [59] in 1915. Douslin and McCullough [60] in 1963, using an inclined dead-weight piston gage, made measurements to $-30{ }^{\circ} \mathrm{C}$. Jancso, Pupezin, and Van Hook [61] in 1970 used a differential capacitance manometer to effect a series of determinations to $-78{ }^{\circ} \mathrm{C}$. They used the vapor pressure of ice at $0{ }^{\circ} \mathrm{C}$ as the reference pressure for their manometer, assigning to th the value $4.581 \mathrm{~mm} \mathrm{Hg}(610.7 \mathrm{~Pa})$.

A comparison of eq (54) with these measurements, excluding the early work of Regnault, Fischer, Juhlin, and Marvin, is shown in figure 1 . The temperatures given by the investigators were converted to IPTS-68 for this comparison. Many of the errors associated with these measurements are not given explicitly so it is difficult to determine both their sources and magnitudes. Therefore, no attempt has been made to assign uncertainties nor to make corrections except for the temperature scale and, where noted, for reference pressure. Because the Jancso, Pupezin and Van Hook pressure measurements were made with respect to the vapor pressure at the ice point they were adjusted to conform to the vapor pressure at $0{ }^{\circ} \mathrm{C}$ predicted by eq (54), namely, 611.154 Pa rather than 610.7 $\mathrm{Pa}(4.581 \mathrm{~mm} \mathrm{Hg}$ ) which Jancso, Pupezin, and Van Hook used.

The sets of data of some of the investigators tend to deviate from eq (54) in consistent ways. The Scheel and Heuse measurements (black dots) are generally lower in magnitude (except for two points) than the vapor pressures calculated from eq (54); the differences increase until at $-67{ }^{\circ} \mathrm{C}$ they are of the order of 70 percent. Weber's measurements (pluses) are much closer, but they also are lower in magnitude (except for two points); at about $-98{ }^{\circ} \mathrm{C}$, where suprisingly Weber obtained several measurements, the deviations are as large as 25 percent. Among all the investigators, the best agreement is achieved with Weber. However, Weber made no measurements above $-22{ }^{\circ} \mathrm{C}$.

Of the three measurements of Nernst (black squares) two (at -30 and $-50{ }^{\circ} \mathrm{C}$ ) show positive differences and the third (at $-40{ }^{\circ} \mathrm{C}$ ) a negative difference, none exceeding 2 percent. The Drucker, Jimeno, and Kangro measurements (black triangles) tend to be high, with one value (at $-34{ }^{\circ} \mathrm{C}$ ) differing by as much as +12.3 percent. The differences for the Douslin and McCullough measurements (asterisks), which cover the range of temperature from -2 to $-31.4{ }^{\circ} \mathrm{C}$, are almost equally positive and negative in number and reach a magnitude of about one percent at $-31.4{ }^{\circ} \mathrm{C}$. The Jancso, Pupezin, and Van Hook differences (circles) scatter more or less randomly in the temperature region above $-15{ }^{\circ} \mathrm{C}$; from $-35^{\circ} \mathrm{C}$ and below, the differences are all positive, reaching a magnitude of 20 percent at about $-78{ }^{\circ} \mathrm{C}$.

The differences far exceed the estimated uncertainty of the values predicted by eq (54). It may be inferred from the difference patterns displayed by these several sets of data that there are significant systematic errors present in each of these data. The obvious conclusion is that a definitive set of measurements remains to be made.

Numerous empirical equations have been proposed to represent the vapor pressure of ice. Scheel and Heuse [54] and Thiesen [62] derived formulas which fit the original Scheel and Heuse data [54]. The equations of Tetens [63] and Erdelyszky as given by Sonntag [64], are of the Magnus type [65] with different sets of coefficients. The Jancso, Pupezin, and Van Hook [61] empirical equation is based on a least square fit to their own measurements. 

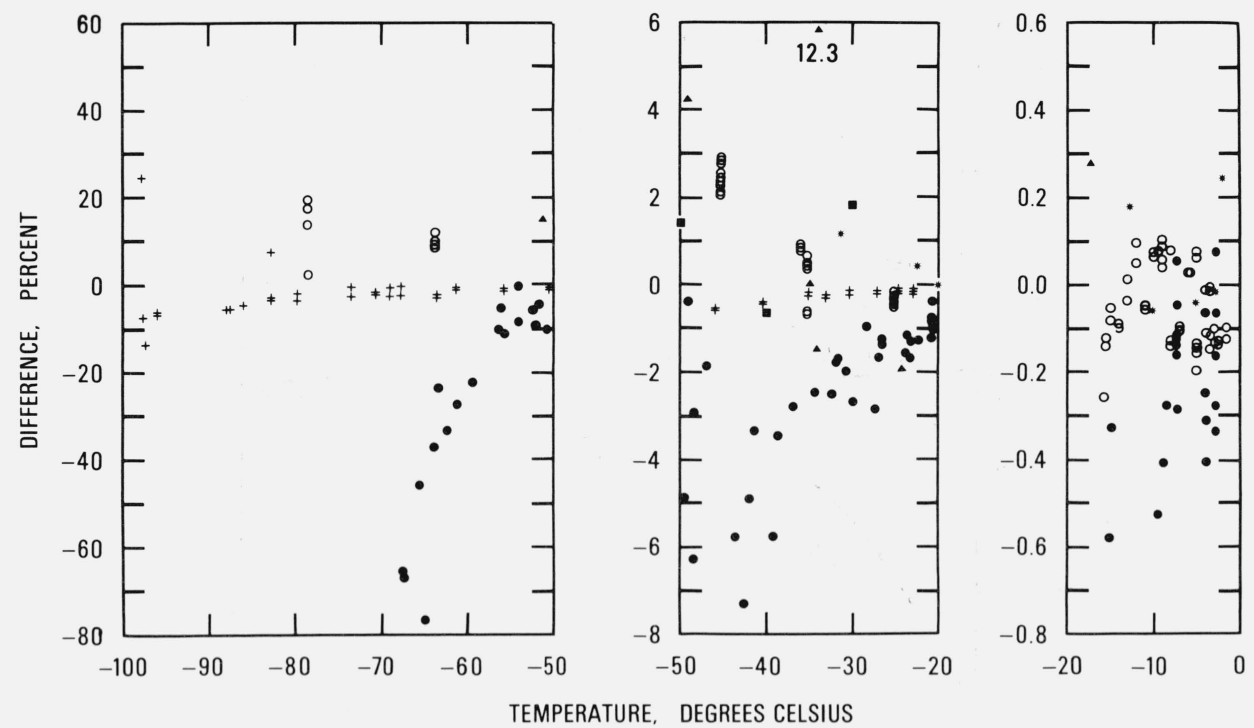

TEMPERATURE, DEGREES CELSIUS

FIGURE 1. Comparision with vapor pressure measurements. Relative vapor pressure difference $\left[\frac{\text { measurement }- \text { eq }(54)}{\text { eq }(54)} \times 100\right]$ between measurement and eq (54) in percent: $\bullet$ Scheel and Heuse; + Weber;

- Nernst; $\Delta$ Drucker, Jimeno and Kangro; * Douslin and McCullough; $\bigcirc$ Jancso, Pupezin and Van Hook.

There also have been repeated attempts to derive thermodynamically based expressions for the vapor pressure of ice. The equations of Nernst [58], Washburn [66], Whipple [67], and Goff and Gratch [68, 69] were obtained by integrating the Clausius-Clapeyron equation and inserting selected values of thermal data. Vapor pressures based on the Nernst equation were included in an early edition of the Smithsonian Meteorological Tables [70]. Vapor pressures based on the Washburn equation are given in several standard references [71, 72] often used by chemists. The Goff formulation is used in the meteorological and air conditioning disciplines [73-75]. The equation ascribed to Kelley [76] is based on an expression he derived for the free energy difference which, when integrated with respect to temperature, yields the logarithm of the vapor pressure. This equation is given in a widely used set of German tables [77] and by Dushman [78]. The equations of Miller [79] and Jancso, Pupezin, and Van Hook [61] were derived from an expression for the vaporization process given in terms of vapor fugacity and condensed phase activity [80]. The Miller equation was not presented in explicit form although calculated vapor pressures were given in an abbreviated table.

A comparison between the empirical equations and eq (54) is shown in figure 2 and a similar comparison between the thermodynamic equations and eq (54) is shown in figure 3 . Because the Thiesen and the Whipple equations give functional relationships for the ratio $p / p_{0}$, where $p$ is the vapor pressure at any given temperature and $p_{0}$ is the vapor pressure at $0{ }^{\circ} \mathrm{C}$, the value predicted by eq $(54)$ was inserted for $p_{0}$ to compute $p$ rather than the value used by these investigators. No attempt was made to adjust or correct any of the empirical equations from the temperature scale used by the investigator in his formulation to IPTS-68.

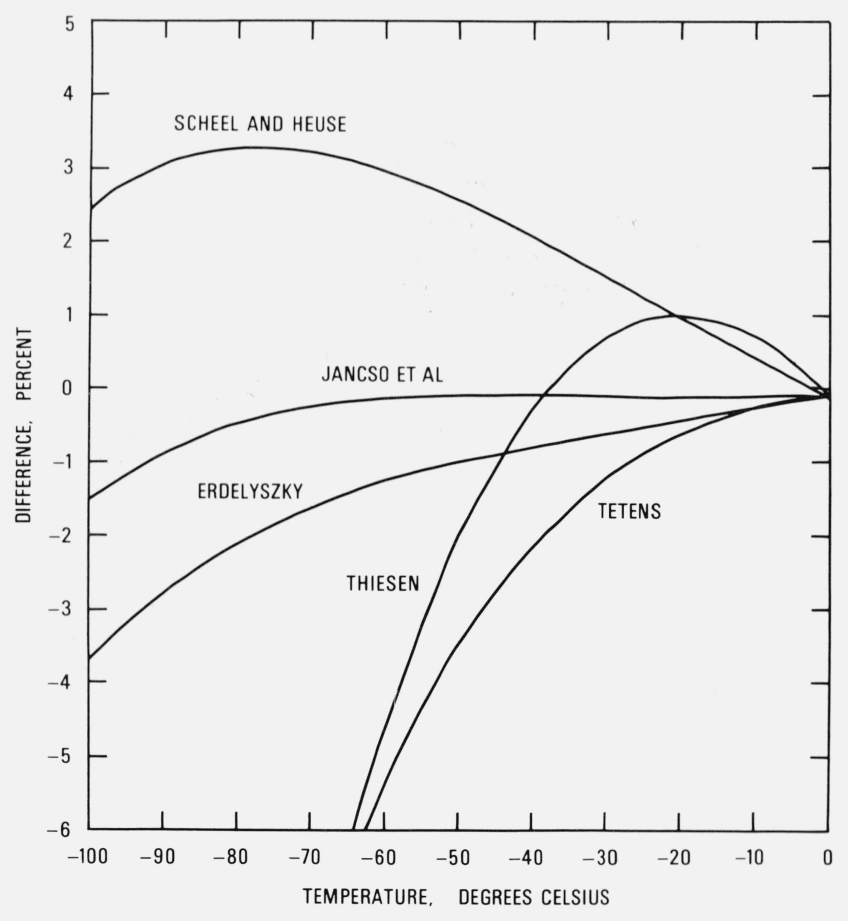

FIGURE 2. Comparison with empirical equations.

Relative vapor pressure difference $\left[\frac{\text { other }- \text { eq }(54)}{\text { eq }(54)} \times 100\right]$ between empirical equation cited in the literature and eq (54) in percent. 


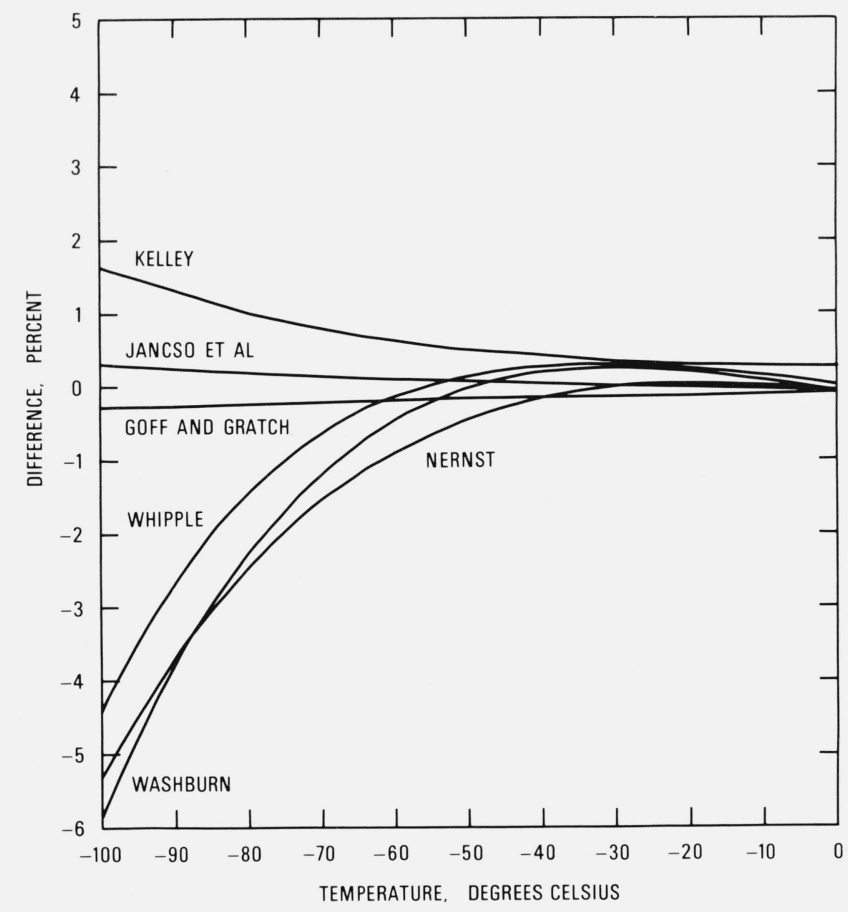

FIGURE 3. Comparison with thermodynamic equations. Relative vapor pressure difference $\left[\frac{\text { other }- \text { eq }(54)}{\text { eq }(54)} \times 100\right]$ between thermodynamic equation

All the empirical formulations, except that of Jancso, Pupezin, and Van Hook, deviate substantially from eq (54). This, in part, may be accounted for by errors in the temperature scale. More important, however, is the fact that these equations were fitted to experimental data and it has already been demonstrated (see fig. 1) that there are significant differences between those data and eq (54). On the other hand, the Jancso, Pupezin, and Van Hook data differ randomly from eq (54) above $-15^{\circ} \mathrm{C}$. Therefore, it is reasonable to expect their empirical equation to agree closely with eq (54) in this region, as indeed it does. What is not clear is why at lower temperatures, say from -50 to $-80{ }^{\circ} \mathrm{C}$, the differences between their equation and eq (54) are negative whereas the differences between their measurements and eq (54) are positive. No significance is attached to the differences below $-80{ }^{\circ} \mathrm{C}$ because their equation was not fitted to data at these lower temperatures and hence is an extrapolation.

There is much better accord between the thermodynamic equations and eq $(54)$, at least down to about $-40{ }^{\circ} \mathrm{C}$. Below $-40{ }^{\circ} \mathrm{C}$ the Kelley, Whipple, Nernst, and Washburn equations deviate increasingly from eq $(54)$; at $-100{ }^{\circ} \mathrm{C}$, they differ from eq (54) by $+1.6,-4.4,-5.4$, and -5.8 percent, respectively. There is good agreement between the Goff and Gratch equation and eq (54); the former yields calculated values that are smaller by 0.08 percent at $0{ }^{\circ} \mathrm{C}$ and by 0.29 percent at $-100{ }^{\circ} \mathrm{C}$. There is also good agreement between the Jancso, Pupezin, and Van Hook equation and eq (54); the vapor pressures from their thermodynamic calculations are smaller by 0.06 percent at $0{ }^{\circ} \mathrm{C}$ but are larger by 0.31 percent at $-100^{\circ} \mathrm{C}$. The vapor pressures from the Goff and Gratch equation and the Jancso, Pupezin and Van Hook equation straddle both sides of those derived from eq (54).

\section{Tabulations}

Vapor pressures were computed from eq (54) and are given in pascals as a function of temperature (in degrees Celsius on the IPTS-68 scale) at 0.1 -degree intervals from 0 to $-100{ }^{\circ} \mathrm{C}$. These computed values, as well as the derivative with respect to temperature at intervals of 1 degree $\mathrm{C}$, are given in table 6 .

\section{Discussion}

Two equations are offered for use by those who wish to compute the vapor pressure rather than to select or interpolate it from tabulated values. Equation (54) is the preferred equation because it has a rational thermodynamic basis. If a simpler form is desired, then eq (63) may be used, but it should be remembered that the latter equation is empirical. Although the vapor pressures in table 6 are given to six significant figures, the accuracy ascribed to these values is no better than that listed in table 5. Finally, because of the truncating procedure used in the calculation, the last significant figure may differ by 1 from the best rounded value. 
TABLE 6. Saturation vapor pressure over ice

\begin{tabular}{|c|c|c|c|c|c|c|c|c|c|c|c|}
\hline Deg & 0.0 & 0.1 & 0.2 & 0.3 & 0.4 & 0.5 & 0.6 & 0.7 & 0.8 & 0.9 & Derivative \\
\hline C & $\mathrm{Pa}$ & $\mathrm{Pa}$ & $\mathrm{Pa}$ & $\mathrm{Pa}$ & $\mathrm{Pa}$ & $\mathrm{Pa}$ & $\mathrm{Pa}$ & $\mathrm{Pa}$ & $\mathrm{Pa}$ & $\mathrm{Pa}$ & $\mathrm{Pa} / \mathrm{K}$ \\
\hline-0 & 611.153 & 606.140 & 601.164 & 596.225 & 591.323 & 586.458 & 581.630 & 576.837 & 572.081 & 567.360 & 48.7738 \\
\hline-1 & 562.675 & 558.025 & $553.411 ।$ & 548.830 & 544.285 & 539.774 & 535.297 & 530.853 & 526.444 & 522.067 & 45.2441 \\
\hline-2 & 517.724 & 513.414 & 509.136 & 504.891 & 500.679 & 496.498 & 492.349 & 488.232 & 484.146 & 480.091 & 41.9451 \\
\hline-3 & 476.068 & 472.075 & 468.112 & 464.180 & 460.278 & 456.406 & 452.564 & 448.751 & 444.968 & 441.213 & 38.8634 \\
\hline-4 & 437.488 & 433.791 & 430.123 & 426.483 & 422.871 & 419.287 & 415.731 & 412.202 & 408.700 & 405.226 & 35.9864 \\
\hline-5 & 401.779 & 398.358 & 394.964 & 391.597 & 388.256 & 384.940 & 381.651 & 378.387 & 375.149 & 371.936 & 33.3021 \\
\hline-6 & 368.748 & 365.585 & 362.446 & 359.333 & 356.244 & 353.179 & 350.138 & 347.121 & 344.128 & 341.158 & 30.7990 \\
\hline-7 & 338.212 & 335.289 & 332.389 & 329.512 & 326.658 & 323.826 & 321.017 & 318.230 & 315.465 & 312.722 & 28.4662 \\
\hline-8 & 310.001 & 307.302 & 304.624 & 301.967 & 299.332 & 296.717 & 294.124 & 291.551 & 288.998 & 286.467 & 26.2936 \\
\hline-9 & 283.955 & 281.464 & 278.992 & 276.540 & 274.108 & 271.696 & 269.303 & 266.929 & 264.575 & 262.239 & 24.2713 \\
\hline-10 & 259.922 & 257.624 & 255.345 & 253.084 & 250.841 & 248.617 & 246.410 & 244.222 & 242.051 & 239.898 & 22.3900 \\
\hline-11 & 237.762 & 235.644 & 233.543 & 231.459 & 229.393 & 227.343 & 225.310 & 223.293 & 221.293 & 219.309 & 20.6412 \\
\hline-12 & 217.342 & 215.391 & 213.456 & 211.537 & 209.633 & 207.745 & 205.873 & 204.017 & 202.175 & 200.349 & 19.0163 \\
\hline-13 & 198.538 & 196.742 & 194.961 & 193.194 & 191.442 & 189.705 & 187.982 & 186.274 & 184.579 & 182.899 & 17.5077 \\
\hline-14 & 181.233 & 179.581 & 177.942 & 176.318 & 174.706 & 173.109 & 171.524 & 169.953 & 168.396 & 166.851 & 16.1079 \\
\hline-15 & 165.319 & 163.800 & 162.294 & 160.801 & 159.320 & 157.852 & 156.396 & 154.952 & 153.521 & 152.101 & 14.8099 \\
\hline-16 & 150.694 & 149.299 & 147.915 & 146.544 & 145.184 & 143.835 & 142.498 & 141.173 & 139.858 & 138.555 & 13.6070 \\
\hline-17 & 137.263 & 135.982 & 134.713 & 133.453 & 132.205 & 130.968 & 129.741 & 128.524 & 127.318 & 126.123 & 12.4932 \\
\hline-18 & 124.938 & 123.763 & 122.598 & 121.443 & 120.298 & 119.163 & 118.038 & 116.923 & 115.817 & 114.721 & 11.4624 \\
\hline-19 & 113.634 & 112.557 & 111.489 & 110.431 & 109.381 & 108.341 & 107.310 & 106.288 & 105.275 & 104.271 & 10.5091 \\
\hline-20 & 103.276 & 102.289 & 101.311 & 100.341 & 99.3809 & 98.4284 & 97.4843 & 96.5485 & 95.6210 & 94.7016 & 9.62823 \\
\hline-21 & 93.7904 & 92.8872 & 91.9920 & 91.1047 & 90.2253 & 89.3537 & 88.4898 & 87.6336 & 86.7850 & 85.9439 & 8.81467 \\
\hline-22 & 85.1104 & 84.2842 & 83.4655 & 82.6540 & 81.8498 & 81.0528 & 80.2629 & 79.4801 & 78.7043 & 77.9355 & 8.06388 \\
\hline-23 & 77.1735 & 76.4184 & 75.6701 & 74.9286 & 74.1937 & 73.4655 & 72.7438 & 72.0286 & 71.3199 & 70.6176 & 7.37151 \\
\hline-24 & 69.9217 & 69.2321 & 68.5487 & 67.8716 & 67.2005 & 66.5356 & 65.8768 & 65.2239 & 64.5770 & 63.9360 & 6.73347 \\
\hline-25 & 63.3008 & 62.6715 & 62.0479 & 61.4300 & 60.8178 & 60.2112 & 59.6101 & 59.0146 & 58.4245 & 57.8399 & 6.14595 \\
\hline-26 & 57.2607 & 56.6868 & 56.1182 & 55.5548 & 54.9966 & 54.4436 & 53.8958 & 53.3530 & 52.8152 & 52.2824 & 5.60533 \\
\hline-27 & 51.7546 & 51.2317 & 50.7136 & 50.2003 & 49.6919 & 49.1882 & 48.6892 & 48.1948 & 47.7051 & 47.2199 & 5.10825 \\
\hline-28 & 46.7393 & 46.2632 & 45.7916 & 45.3244 & 44.8616 & 44.4031 & 43.9489 & 43.4991 & 43.0534 & 42.6120 & 4.65155 \\
\hline-29 & 42.1748 & 41.7417 & 41.3126 & 40.8877 & 40.4667 & 40.0498 & 39.6368 & 39.2278 & 38.8226 & 38.4213 & 4.23227 \\
\hline-30 & 38.0238 & 37.6301 & 37.2402 & 36.8540 & 36.4714 & 36.0926 & 35.7173 & 35.3457 & 34.9776 & 34.6131 & 3.84764 \\
\hline-31 & 34.2521 & 33.8945 & 33.5404 & 33.1897 & 32.8423 & 32.4983 & 32.1577 & 31.8203 & 31.4862 & 31.1554 & 3.49509 \\
\hline-32 & 30.8277 & 30.5032 & 30.1819 & 29.8637 & 29.5486 & 29.2365 & 28.9275 & 28.6215 & 28.3185 & 28.0185 & 3.17218 \\
\hline-33 & 27.7214 & 27.4272 & 27.1358 & 26.8474 & 26.5617 & 26.2789 & 25.9988 & 25.7215 & 25.4469 & 25.1751 & 2.87668 \\
\hline-34 & 24.9059 & 24.6394 & 24.3755 & 24.1142 & 23.8555 & 23.5993 & 23.3457 & 23.0947 & 22.8461 & 22.5999 & 2.60647 \\
\hline-35 & 22.3563 & 22.1150 & 21.8762 & 21.6397 & 21.4056 & 21.1739 & 20.9444 & 20.7173 & 20.4924 & 20.2698 & 2.35960 \\
\hline-36 & 20.0494 & 19.8312 & 19.6152 & 19.4014 & 19.1898 & 18.9803 & 18.7729 & 18.5675 & 18.3643 & 18.1631 & 2.13424 \\
\hline-37 & 17.9640 & 17.7669 & 17.5717 & 17.3786 & 17.1874 & 16.9982 & 16.8108 & 16.6254 & 16.4419 & 16.2603 & 1.92868 \\
\hline-38 & 16.0805 & 15.9025 & 15.7264 & 15.5521 & 15.3795 & 15.2088 & 15.0397 & 14.8725 & 14.7069 & 14.5430 & 1.74136 \\
\hline-39 & 14.3809 & 14.2204 & 14.0615 & 13.9043 & 13.7488 & 13.5948 & 13.4424 & 13.2916 & 13.1424 & 12.9947 & 1.57080 \\
\hline-40 & 12.8486 & 12.7040 & 12.5609 & 12.4192 & 12.2791 & 12.1404 & 12.0032 & 11.8674 & 11.7330 & 11.6000 & 1.41564 \\
\hline-41 & 11.4685 & 11.3383 & 11.2095 & 11.0820 & 10.9559 & 10.8311 & 10.7076 & 10.5854 & 10.4645 & 10.3449 & 1.27461 \\
\hline-42 & 10.2266 & 10.1095 & 9.99366 & 9.87903 & 9.76563 & 9.65343 & 9.54243 & 9.43260 & 9.32395 & 9.21646 & 1.14655 \\
\hline-43 & 9.11011 & 9.00490 & 8.90082 & 8.79785 & 8.69598 & 8.59521 & 8.49552 & 8.39690 & 8.29934 & 8.20283 & 1.03036 \\
\hline-44 & 8.10736 & 8.01292 & 7.91950 & 7.82708 & 7.73567 & 7.64525 & 7.55580 & 7.46733 & 7.37981 & 7.29325 & 0.925056 \\
\hline-45 & 7.20763 & 7.12294 & 7.03917 & 6.95631 & 6.87436 & 6.79330 & 6.71313 & 6.63384 & 6.55542 & 6.47785 & .829693 \\
\hline-46 & 6.40114 & 6.32526 & 6.25022 & 6. 17601 & 6.10262 & 6.03003 & 5.95824 & 5.88725 & 5.81704 & 5.74761 & .743420 \\
\hline-47 & 5.67894 & 5.61104 & 5.54389 & 5.47749 & 5.41182 & 5.34688 & 5.28267 & 5.21917 & 5.15638 & 5.09429 & .665446 \\
\hline-48 & 5.03290 & 4.97219 & 4.91216 & 4.85280 & 4.79411 & 4.73608 & 4.67870 & 4.62196 & 4.56587 & 4.51040 & .595041 \\
\hline-49 & 4.45556 & 4.40134 & 4.34773 & 4.29473 & 4.24233 & 4.19052 & 4.13930 & 4.08866 & 4.03860 & 3.98910 & .531534 \\
\hline-50 & 3.94017 & 3.89179 & 3.84397 & 3.79669 & 3.74996 & 3.70375 & 3.65808 & 3.61293 & 3.56829 & 3.52417 & .474306 \\
\hline-51 & 3. 48056 & 3.43744 & 3.39483 & 3.35270 & 3.31106 & 3.26990 & 3.22921 & 3.18900 & 3.14925 & 3.10996 & .422790 \\
\hline-52 & 3.07113 & 3.03275 & 2.99481 & 2.95731 & 2.92025 & 2.88362 & 2.84742 & 2.81165 & 2.77628 & 2.74134 & .376464 \\
\hline
\end{tabular}


TABLE 6. Saturation vapor pressure over ice - continued

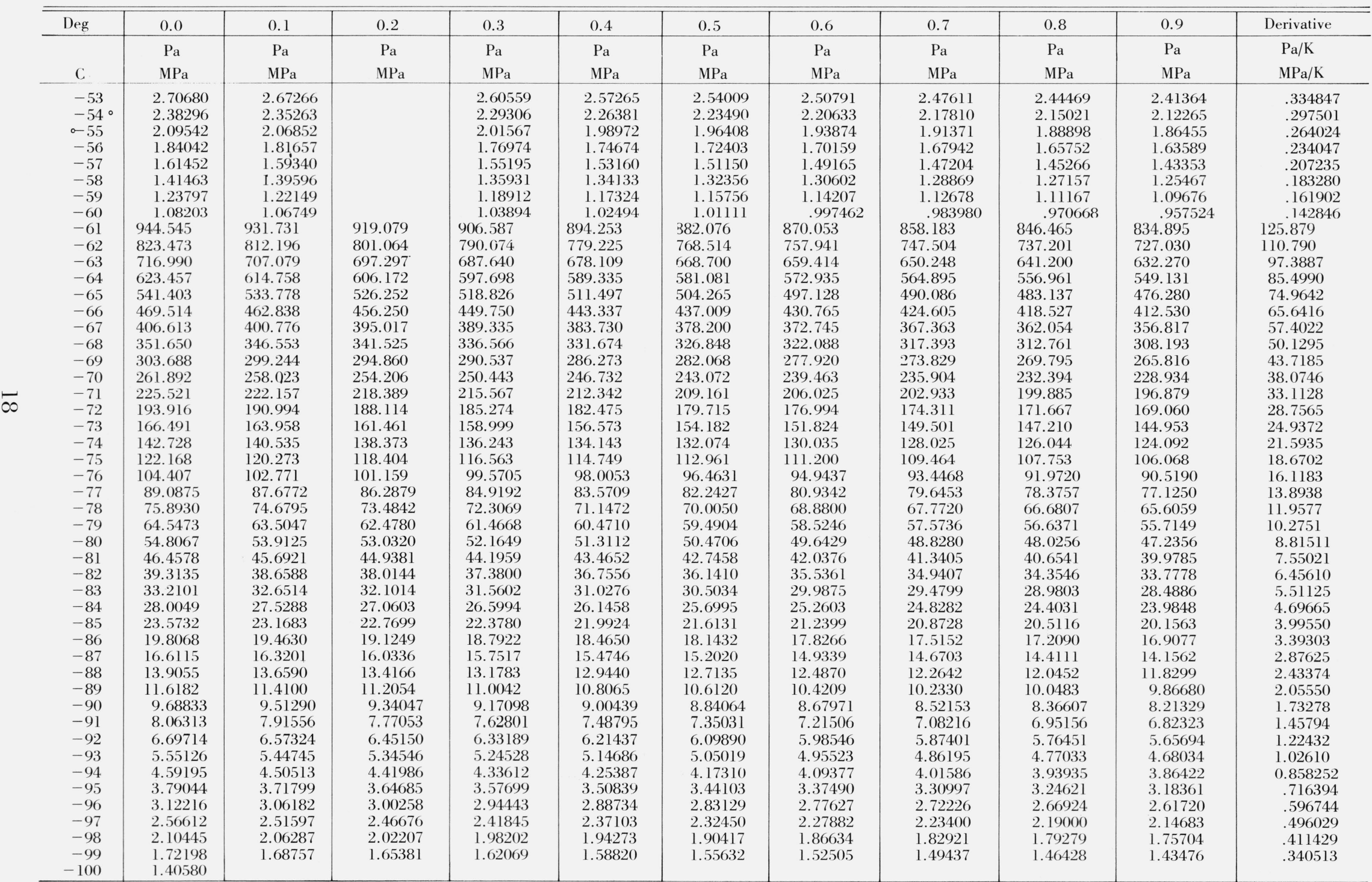




\section{References}

[1] Wexler, A., and Greenspan, L., Vapor pressure equation for water in the range 0 to $100{ }^{\circ} \mathrm{C}$, J. Res. Nat. Bur. Stamd. (U.S.), 75A (Phys and Chem.), No.3, 213-230 (May-June 1971).

[2] Stimson, H. F., Some precise measurements of the vapor pressure of water in the range from 25 to $100{ }^{\circ} \mathrm{C}$, Nat. Bur. Stand. (U.S.), 73A (Phys. and Chem.), No. 5, 493-496 (Sept.-Oct. 1969).

[3] Wexler, A., Vapor pressure equation for water in the range 0 to $100{ }^{\circ} \mathrm{C}$. A revision, J. Res. Nat. Bur. Stand. (U:S.), 80A (Phys. and Chem.), No. 5, (Sept.-Oct. 1976).

[4] Guildner, L., Johnson, D. P., and Jones, F. E., Vapor pressure of water at its triple point, Nat. Bur. Stand. (U.S.), 80A, (Phys. and Chem.), No. 3, 505-521 (Mav-June 1976).

[5] Guildner, L. and Edsinger, R. E., Deviation of international practical temperatures from thermodynamic temperatures in the temperature range from $273.16 \mathrm{~K}$ to $730 \mathrm{~K}$, J. Res. Nat. Bur. Stand. (U.S.), 80A (Phys. and Chem.), No. 5, 703(Sept.-Oct. 1976).

[6] The international practical temperature scale of 1968, Metrologia 5, 35 (1969)

[7] Burgess, G. K., The international temperature scale, J. Res. Nat. Bur. Stand. (U.S.), 1, 635-640 (1928) RP22.

[8] Stimson, H. F., International temperature scale of 1948, J. Res. Nat. Bur. Stand. (U.S.), 42, 209-217 (1949) RP1962.

[9] Stimson, H. F., International practical temperature scale of 1948. Text revision of 1960. J. Res. Nat. Bur. Stand. (U.S.), 65A (Phys. and Chem.), No. 3, 139-145 (1961).

[10] Douglas, T. B., Conversion of existing calorimetrically determined thermodynamic properties to the basis of the international practical temperature scale of 1968, J. Res. Nat. Bur. Stand. (U.S.), 73A (Phys. and Chem.), No. 5, 451-470 (Sept.-Oct. 1969).

[11] Riddle, J. L., Furukawa, G. T., and Plumb, H. H., Platinum resistance thermometry, NBS Monograph 126, Supt. of Documents, Government Printing Office, Washington, D. C. 20402, (April 1973).

[12] Goff, J. A., and Gratch, S., Thermodynamic properties of moist air, Heating, Piping and Air Conditioning, ASHVE Journal Section 17, 334 (1945).

[13] Goff, J. A., and Gratch, S., Low-pressure properties of water from - 160 to $212 \mathrm{~F}$. Trans. ASHVE 52, 95 (1946).

[14] Goff, J. A., Standardization of thermodynamic properties of moist air, Heating, Piping and Air Conditioning, ASHVE Journal Section 21 , 118 (1949).

[15] Keyes, F. G., The thermodynamic properties of water substance $0^{\circ}$ to $150^{\circ} \mathrm{C}$, J. Chem. Phys. 15, 602 (1947).

[16] Keenan, J. H., Keyes, F. G., Hill, P. G., and Moore, J. G., Steam Tables (John Wiley \& Sons, Inc., New York, 1969).

[17] Bain, R. W., Steam Tables, 1964 (Her Majesty's Stationery Office, Edinburgh, 1964).

[18] Dorsey, N. E., Properties of Ordinary Water-substance (Reinhold Pub. Corp., New York, 1940).

[19] Ginnings, D. C., and Corruccini, R. J., An improved ice calorimeterthe determination of its calibration factor and the density of ice at 0 ${ }^{\circ} \mathrm{C}$, J. Res. Nat. Bur. Stand. (U.S.), 38, 583-591 (1947) RP1796.

[20] Jakob, M., and Erk, S., Wärmedehnung des Eises zwischen 0 und $-253^{\circ}$, Wiss. Abh. Physik.-Techn. Reichsanst. 12, 301 (192829).

[21] Powell, R. W., Preliminary measurements of the thermal conductivity and expansion of ice. Proc. Roy. Soc. A247, 464 (1958).

[22] Butkovich, T. R., Thermal expansion of ice, J. App. Phys. 30, 350 (1959).

[23] Dantl, Gerhard, Wärmeausdehnung von $\mathrm{H}_{2} \mathrm{O}$ - und $\mathrm{D}_{2} \mathrm{O}$-Einkristallen, Z. fur Phys. 166, 115 (1962).

[24] LaPlaca, S. and Post, B., Thermal expansion of ice, Acta Cryst. 13, $503(1960)$.

[25] Judson, L. V., Units of weight and measure. Definitions and tables of equivalents, NBS Misc. Pub. M214, (1955), U. S. Gov't Printing Office, Washington, D. C.

[26] Zemansky, M. W., Heat and Thermodynamic (McGraw-Hill, New York, 1951).

[27] Leadbetter, A. J., The thermodynamic and vibrational properties of $\mathrm{H}_{2} \mathrm{O}$ ice and $\mathrm{D}_{2} \mathrm{O}$ ice, Proc. Roy. Soc. A287, 403 (1965).

[28] Nernst, W., Koref, F., and Lindemann, F. A., Untersuchungen über die specifische Wärme bei tiefen Temperaturen, Sitz. Akad. Wiss. Berlin 3, 247 (1910).
[29] Pollitzer, F., Bestimmung spezifischer Wärmen bei tiefen Temperaturen und ihre Verwertung zur Berechnung elektromotorischer Kräfte, Zeit. für Elektrochemie 17, 5 (1911); 19, 513 (1913).

[30] Dickinson, H. C., and Osborne, N. S., Specific heat and heat of fusion of ice, Bull. Bur. Stds. 12, 49 (1915).

[31] Maass, O., and Waldbauer, L. J., The specific heats and latent heats of fusion of ice and of several organic compounds, J.' Amer. Chem. Soc. 47, 1 (1925).

[32] Barnes, W. H., and Maass, O., Specific heats and latent heat of fusion of ice, Can. J. Res. 3, 205 (1930).

[33] Barnes, W. H., and Maass, O., A new adiabatic calorimeter, Can. J. Res. 3, 70 (1930).

[34] Giauque, W. F., and Stout, J. W., The entropy and the third law of thermodynamics. The heat capacity of ice from 15 to $273^{\circ} \mathrm{K}, \mathrm{J}$. Amer. Chem. Soc. 58, 1144 (1936).

[35] Sugisaki, M., Suga, H., and Seki, S., Calorimetric study of the glassy state. IV. Heat capacities of glassy water and cubic ice, Bull. Chem. Soc. Japan 41, 2591 (1968).

[36] Osborne, N. S., Heat of fusion of ice. A revision, J. Res. Nat. Bur. Stand. (U.S.), 23, 643-646 (1939) RP1260.

[37] Friedman, A. S., and Haar, L., High-speed machine computation of ideal gas thermodynamic functions. I. Isotopic water molecules, J. Chem. Phys. 22, 2051 (1954).

[38] Osborne, N. S., Calorimetry of a fluid, J. Res. Nat. Bur. Stand. (U.S.), 4, 609-629 (1930) RP168.

[39] Fiock, E. F., and Ginnings, D. C., Heat of vaporization of water at $50^{\circ}$, $70^{\circ}$ and $90^{\circ} \mathrm{C}$, J. Res. Nat. Bur. Stand. (U.S.), 8, 321-324 (1932) RP416.

[40] Osborne, N. S., Stimson, H. F., and Ginnings, D. C., Calorimetric determination of the thermodynamic properties of saturated water in both the liquid and gaseous states from $100^{\circ}$ to $374{ }^{\circ} \mathrm{C}$, J. Res. Nat. Bur. Stand. (U.S.), 18, 389-431 (1937) RP983.

[41] Osborne, N. S., Stimson, H. F., and Ginnings, D. C., Measurements of heat capacity and heat of vaporization of water in the range $0^{\circ}$ to $100^{\circ}$ C, J. Res. Nat. Bur. Stand. (U.S.), 23, 197-260 (1939) RP1228.

[42] Kell, G. S., Precise representation of volume properties of water at one atmosphere, J. Chem. Eng. Data 12, 66 (1967).

[43] Cohen, E. R. and Taylor, B. N., Fundamental physical constants, J. Phys. Chem. Ref. Data 2, 663 (1973).

[44] Eisenberg, D. and Kauzman, W., The Structure of Water, Oxford (University, Press, New York and Oxford, 1969).

[45] Shatenshtein, A. I., Yakovleva, E. A., Zvyagintseva, E. N., Varshavskii, Ya. M., Israilevich, E. J., and Dykhno, N. M., Isotopic Analysis of Water, United States Atomic Energy Commission translation AEC-tr-4136 (1960).

[46] International Union of Pure and Applied Chemistry Commission on Atomic Weights, Atomic Weights of the Elements, Pure and Applied Chem. 37, 591-603 (1974).

[47] Abramowitz, M. and Stegun, I. A., Handbook of Mathematical Functions, NBS Appl. Math. Ser. 55, 885 (June 1964), U. S. Gov't Printing Office, Washington, D. C. 20402.

[48] Natrella, M. G., Experimental Statistics, NBS Handbook 91 (1963), U. S. Gov't Printing Office, Washington, D. C. 20402.

[49] Ku, H. H., Notes on the use of propagation of error formulas, J. Res. Nat. Bur. Stand. (U.S.), 70C (Eng. and Instr.) No. 4, 263-273 (Oct.-Dec. 1966).

[50] Regnault, V., Huitième Memoire. Des forces elastiques de la vapeur d'eau aux differentes temperatures, Memoires de l'Académie des Sciences de l'Institut de France, Paris 21, 465 (1947).

[51] Fischer, W., Über die Tension der über flussiger und der über fester Substanz gesättigter Dampfe, Ann. Physik Chem. 28, 400 (1886).

[52] Juhlin, J., Bestämming of Vattenängangs Maximi-Spängstighet öfver is mellan $0^{\circ}$ och $-50^{\circ}$ Cels samt över vattern mellan +20 och $-13^{\circ} \mathrm{C}$, Bihang till K. Svenska Vet. - Kad. Handlingar. Stockholm 17, Afd. I. Nr. 1 (1891).

[53] Marvin, C. F., Annual Report of the Chief Signal Officer, Appendix No. 10, 351-383 (1891).

[54] Scheel, K., and Heuse, W., Bestimmung der Sättigungsdruckes von Wasserdampf unter $0^{\circ}$, Ann. Physik. 29, 729 (1909).

[55] Scheel, K. and Heuse, W., Bestimmung des Sättigungsdruckes von 
Wasserdampf zwischen 0 und $+50^{\circ}$, Ann. Physik IV 31, 715 (1910).

[56] Holborn, L., Scheel, K., and Henning, F., Wärmetabellen (Vieweg und Sohn, 1919).

[57] Weber, S., Investigation relating to the vapour pressure of ice, Communications from the Phys. Lab. Univ. Leiden, No. 150a, (1915).

[58] Nernst, W., Thermodynamische Behandlung einiger Eigenschaften des Wassers, Verh. Deut. Physik. Ges. 11, 313 (1909).

[59] Drucker, C., Jimeno, E., and Kangro, W., Dampfdrucke flüssiger Stoffe bei niedrigen Temperaturen, Zeit. Phys. Chem. 90, 513 (1915).

[60] Douslin, D. R. and McCullough, J. P., An inclined-piston deadweight pressure gage, U. S. Bureau of Mines Rept. of Investigation No. 6149 (1963).

[61] Jancso, G., Pupezin, J., and Van Hook, W. A., The vapor pressure of ice between $+10^{-2}$ and $-10^{2}$, J. Phys. Chem. 74, 2984 (1970).

[62] Thiesen, M., Die Dampfspannung über Eis, Ann. der Phys. (4) 29, 1057 (1909)

[63] Tetens, O., Über einize meteorologische Begriffe, Zeit. für Geophysik 6, $297(1930)$

[64] Sonntag, D., Hygrometrie (Akademie-Verlag, Berlin, 1966).

[65] Magnus, G., Versuche über die Spannkrafte des Wasserdampfes, Ann. Physik. Chem. (Poggendorff) 61, 225 (1844).

[66] Washburn, E. W.. The vapor pressure of ice and of water below the freezing point, Monthly Weather Review 52, 488 (1924).

[67] Whipple, F. J. W.. Formulae for the vapour pressure of ice and water below $0^{\circ} \mathrm{C}$, Monthly Weather Review 55, 131 (1927).

[68] Goff, J. A., Vapor pressure of ice from 32 to -280 F, Trans. ASHVE 48, 299 (1942).

[69] Goff, J. A., Saturation pressure of water on the new kelvin scale. In:
Humidity and Moisture, Vol. III, Wexler, A. and Wildhack, W. A., Eds, 289 (Reinhold Publishing Corp., New York, 1965).

[70] Smithsonian Meteorological Tables, 5th Revised Edition, Smithsonian Institution, Washington (1931).

[71] International Critical Tables, Vol. 3 (McGraw-Hill, New York, 1928).

[72] Handbook of Chemistry and Physics, 46th ed. (Chemical Rubber Pub. Co., Cleveland, 1965).

[73] List, R. J., (ed.) Smithsonian Meteorological Tables, 6th Revised ed., Smithsonian Institution, Washington (1951).

[74] Letestu, S., Ed., International Meteorological Tables, W MO-No. 188. TP. 94, World Meteorological Organization, Geneva (1966).

[75] ASHRAE Guide and Data Book, Fundamentals and Equipment 1961, 1965 and 1966, America Society of Heating (Refrigerating and Air Conditioning Engineers, Inc., New York).

[76] Kelley, K. K., Contributions to the data on theoretical metallurgy, III. The free energies of vaporization and vapor pressures of inorganic substances, Bulletin 383, Bureau of Mines, (1935).

[77] Landolt-Börnstein Tabellen, 6 Auflage, II. (Springer-Verlag, Berlin, 1960).

[78] Dushman, S., Scientific Foundations of Vacuum Technique, (John Wiley \& Sons, Inc., 1949).

[79] Miller, G. A., Accurate calculation of very low vapor pressures: ice, benzene, and carbon tetrachloride, J. Chem. Eng. Data 7, 353 (1962).

[80] Lewis, G. N. and Randall, M., Thermodynamics, revised by Pitzer, K. S., and Brewer, L. B. (McGraw-Hill, New York, 1961).

(Paper 81A1-920) 